\title{
Ground-based remote sensing of thin clouds in the Arctic
}

\author{
T. J. Garrett ${ }^{1}$ and C. Zhao $^{2,3}$ \\ ${ }^{1}$ Department of Atmospheric Sciences, University of Utah, Salt Lake City, Utah, USA \\ ${ }^{2}$ Lawrence Livermore National Laboratories, Livermore, California, USA \\ ${ }^{3}$ College of Global Change and Earth System Science, Beijing Normal University, Beijing, China \\ Correspondence to: T. J. Garrett (tim.garrett@utah.edu)
}

Received: 5 November 2012 - Published in Atmos. Meas. Tech. Discuss.: 30 November 2012

Revised: 18 April 2013 - Accepted: 19 April 2013 - Published: 14 May 2013

\begin{abstract}
This paper describes a method for using interferometer measurements of downwelling thermal radiation to retrieve the properties of single-layer clouds. Cloud phase is determined from ratios of thermal emission in three "microwindows" at $862.5 \mathrm{~cm}^{-1}, 935.8 \mathrm{~cm}^{-1}$, and $988.4 \mathrm{~cm}^{-1}$ where absorption by water vapour is particularly small. Cloud microphysical and optical properties are retrieved from thermal emission in the first two of these micro-windows, constrained by the transmission through clouds of primarily stratospheric ozone emission at $1040 \mathrm{~cm}^{-1}$. Assuming a cloud does not approximate a blackbody, the estimated $95 \%$ confidence retrieval errors in effective radius $r_{\mathrm{e}}$, visible optical depth $\tau$, number concentration $N$, and water path WP are, respectively, $10 \%, 20 \%, 38 \%$ (55\% for ice crystals), and $16 \%$. Applied to data from the Atmospheric Radiation Measurement programme (ARM) North Slope of Alaska - Adjacent Arctic Ocean (NSA-AAO) site near Barrow, Alaska, retrievals show general agreement with both ground-based microwave radiometer measurements of liquid water path and a method that uses combined shortwave and microwave measurements to retrieve $r_{\mathrm{e}}, \tau$ and $N$. Compared to other retrieval methods, advantages of this technique include its ability to characterise thin clouds year round, that water vapour is not a primary source of retrieval error, and that the retrievals of microphysical properties are only weakly sensitive to retrieved cloud phase. The primary limitation is the inapplicability to thicker clouds that radiate as blackbodies and that it relies on a fairly comprehensive suite of ground based measurements.
\end{abstract}

\section{Introduction}

Arctic clouds play a significant role in the influential, but poorly understood ice-albedo and cloud-radiation feedback mechanisms (Curry et al., 1996; Francis and Hunter, 2006). Changes in Arctic cloudiness can have discernible effects on the surface energy budget (Wang and Key, 2003; Beesley, 2000; Kay et al., 2008, 2012). Lower level Arctic stratiform clouds are regarded as an especially important target for improved numerical simulations (Smith and Kao, 1996; Harrington et al., 2000; Francis and Hunter, 2007; Fridlind et al., 2007; Klein et al., 2009; Morrison et al., 2011).

Observationally, the micro-structures, optical properties and thermodynamic phase of Arctic stratus have been studied previously using space-based remote sensors (Han et al., 1999; Xiong et al., 2002; Wang and Key, 2005; Tietze et al., 2011; Devasthale et al., 2011; Cesana et al., 2012) and in situ aircraft measurements (Dergach et al., 1960; Witte, 1968; Jayaweera and Ohtake, 1982; Curry et al., 2000; Rangno and Hobbs, 2001; Verlinde et al., 2007; Lampert et al., 2009; Jourdan et al., 2010; McFarquhar et al., 2011). In this paper, the focus is on retrievals of cloud microphysical properties using ground-based measurements. There are a variety of methods that can be used here, each with their respective advantages and disadvantages (Comstock et al., 2007). With respect to clouds in the Arctic, one approach applies a combination of solar transmission and microwave radiometer (MWR) liquid water path to obtain cloud optical depth and effective radius, but only during the daylight months (Dong and Mace, 2003a). Millimeter cloud radar (MMCR) retrievals (Shupe et al., 2005, 2006) do not have this restriction and are able to peer inside clouds. However, large ice crystal precipitation particles are often co-located with small 
liquid droplets in Arctic clouds (Hobbs et al., 2001), and this makes interpreting a radar signal more difficult. Lidar depolarisation has been used effectively to constrain the relative contributions of ice and liquid (van Diedenhoven et al., 2009; Bourdages et al., 2009; de Boer et al., 2011; Shupe, 2011). Yet even here, a difficulty is that the backscatter from shortwave lidar is weighted to much smaller particles than microwave radar, and lidar is attenuated much more rapidly by cloud.

A third approach is to use the infrared portion of the spectrum for remote sensing (Turner et al., 2003; Turner and Eloranta, 2008). While limited to thinner clouds, this approach is appealing because, from a climatological standpoint, it is downwelling thermal emission that plays a dominant role in the Arctic surface radiation balance (Beesley, 2000; Francis and Hunter, 2006). Retrievals are based on the part of the electromagnetic spectrum that is coupled to the physics in question.

Here, we modify an infrared technique that was first developed by Mahesh et al. (2001) (hereafter M01) for retrieving the microphysical properties of Antarctic ice clouds, and extend it here to Arctic ice and liquid clouds. Cloud phase is assessed using a newly developed tri-spectral scheme. The method described here is expected to be particularly accurate for three reasons. First, the remote-sensing technique is anchored in two places: measurements of cloud emissivity within the atmospheric window are combined with measured cloud transmittance of $9.6-\mu \mathrm{m}\left(1040 \mathrm{~cm}^{-1}\right)$ ozone emission. Effectively, stratospheric ozone replaces the sun in solar retrieval techniques. Second, retrievals are based on pairs of narrow spectral windows where sensitivity to water vapour is low while maintaining response to a particularly broad range of cloud properties. Third, the absorptivity of ice and liquid at $9.6 \mu \mathrm{m}$ is almost identical, and this constrains errors in retrievals of cloud properties that might be associated with errors in cloud phase identification.

The retrieval method is outlined in Sect. 2. Section 3 describes the measurements used in this study. The error in the retrieval method is analysed in Sect. 4. The retrieval method is evaluated in Sects. 5 and a summary is presented in Sect. 6.

\section{The modified M01 retrieval algorithm}

The algorithm described here is based on retrievals of a cloud particle "effective radius" $\left(r_{\mathrm{e}}\right)$ and an optical depth in the geometric-optics limit at visible wavelengths $(\tau)$. Here, $r_{\mathrm{e}}$ is proportional to the ratio of the bulk ice or liquid volume to the scattering cross-section of the particle, as introduced by Hansen and Travis (1974). The original definition of $r_{\mathrm{e}}$ can be applied equally to all shapes, independent of whether they are spherical droplets or hexagonal ice crystals (Foot, 1988). 1

\footnotetext{
${ }^{1}$ Because ice crystals are not spherical, the concept of effective radius does not relate directly to the ice crystal geometric size.
}

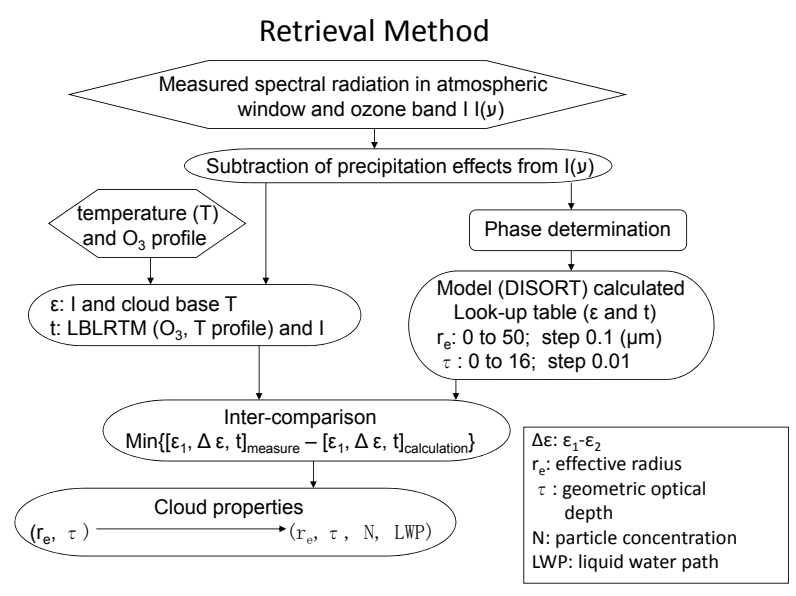

Fig. 1. Diagram illustrating the cloud property retrieval method. The parameters $r_{\mathrm{e}}, \tau, \varepsilon, t, N$ and WP represent effective radius, visible optical depth, cloud emissivity, cloud transmittance, particle concentration and water path, respectively. Cloud phase is determined first based on cloud spectral emissivity and cloud base brightness temperature. A look-up table including $\varepsilon$ and $t$ for a range of $r_{\mathrm{e}}$ and $\tau$ is computed with DISORT for the corresponding phase. Calculated $\varepsilon$ and $t$ are obtained based on measurements. A minimisation of the difference between calculated $\varepsilon$ and $t$ and values in the lookup table is used to obtain $r_{\mathrm{e}}$ and $\tau$. Cloud $N$ and WP are obtained based on a log-normal size distribution and the retrieved values of $r_{\mathrm{e}}$ and $\tau$.

The retrieval process has several important components. Narrow bands or 'micro-windows' are selected in the atmospheric window and ozone band where atmospheric water vapour emission is particularly small. It is by comparing measured values of cloud transmissivity and emissivity in these micro-windows to theoretically estimated values that cloud phase, effective radius and optical depth are inferred. These quantities can be combined to provide cloud water path and, in combination with estimates of cloud thickness, cloud particle concentration. The full retrieval algorithm, including our modifications is illustrated in Fig. 1.

\subsection{Micro-window selection}

For purposes of measurement and calculation of cloud window emissivity, M01 identified seven micro-windows with a width of $2 \mathrm{~cm}^{-1}$ where water vapour absorption is particularly small and with varying sensitivity of particle absorption efficiency $Q_{\mathrm{abs}}$, to particle radius. As shown in Fig. 2, candi-

Rather, it is a length scale used to calculate how efficiently ice crystal mass corresponds to radiative extinction. That said, at the infrared wavelengths considered here, the size parameter $2 \pi r / \lambda$ of cloud ice crystals is sufficiently small to lie below the geometric optics regime where the details of shape become important. 

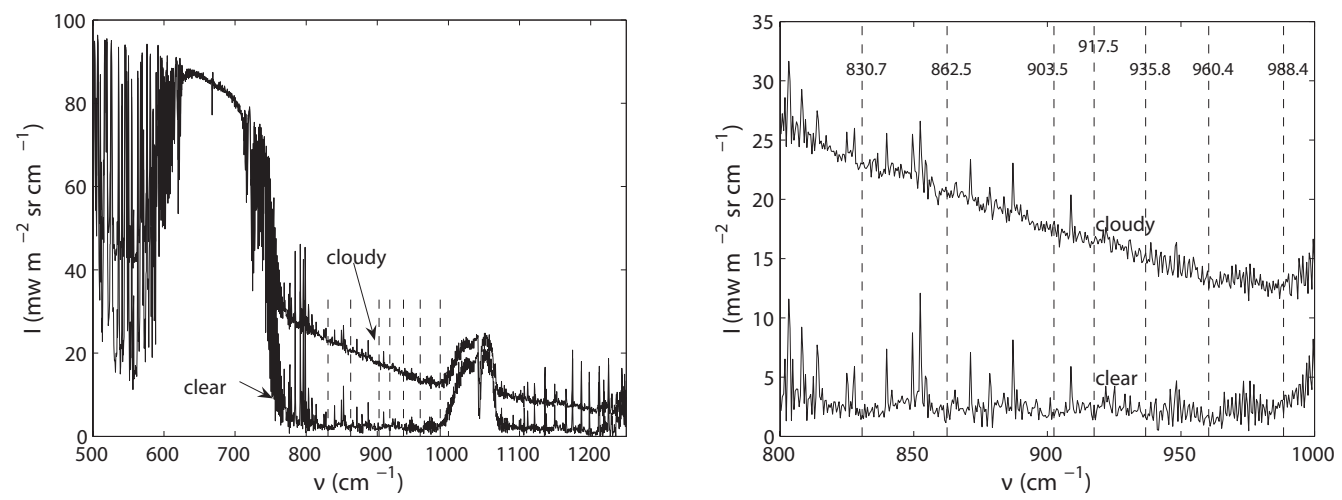

Fig. 2. Selected micro-windows in the atmospheric window, at which atmospheric gases absorption is particularly small. The upper and lower spectral radiation are for cloudy and clear conditions, respectively, measured at ARM NSA-AAO on 7 May 2001.
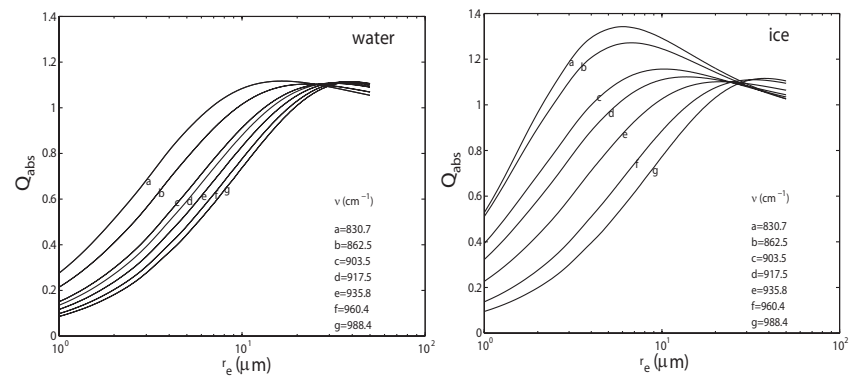

Fig. 3. Water and ice absorption efficiency $Q_{\text {abs }}$ as a function of cloud particle effective size $r_{\mathrm{e}}$ at six different wavenumbers within atmospheric micro-windows where atmospheric gaseous absorption is particularly small.

date micro-windows in the atmospheric window are centred at 830.7 (a), 862.5 (b), 903.5 (c), 917.5 (d), 935.8 (e), 960.4 (f) and $988.4(\mathrm{~g}) \mathrm{cm}^{-1}$. The values of liquid water and ice $Q_{\text {abs }}$ are computed from Mie theory (Wiscombe, 1980) based on their respective complex refractive indices (Warren, 1984; Wieliczka et al., 1989). It is from this set that we determine pairs for which, as shown in Fig. 3, there is varying sensitivity of the water and ice absorption coefficient $\left(Q_{\text {abs }}\right)$ for a particularly wide range of particle radii $(r)(r$ here, as it is applied to ice crystals, is more a radiative length scale than a spherical radius).

As shown in Fig. 3, the sensitivity of $Q_{\text {abs }}$ to $r$ is not the same in every micro-window. To exploit differences in size sensitivity, the retrieval method applied here uses the microwindow wavenumber pair $862.5(b)$ and $935.8 \mathrm{~cm}^{-1}(e)$. For these wavenumbers, a look-up table is calculated for cloud emissivity $\varepsilon$ in the two micro-windows, and cloud transmittance in the ozone band $t$, for various values of $r_{\mathrm{e}}$ and $\tau$ for a range of effective radii $r_{\mathrm{e}}<50 \mu \mathrm{m}$ and visible optical depths $\tau<16$, using the Discrete Ordinates Radiative Transfer code (DISORT; Stamnes et al., 1988). Emissivity and transmissiv- ity are defined by

$$
\begin{aligned}
\varepsilon(v) & =I(v) / B\left(T_{\mathrm{c}}, v\right) \\
t & =1-\varepsilon
\end{aligned}
$$

where $I$ is the radiative intensity and $B\left(T_{\mathrm{c}}\right)$ is the intensity of blackbody radiation for cloud base temperature $T_{\mathrm{c}}$. The calculated value of $\varepsilon(v)$ is an "effective emissivity" that implicitly incorporates the small added component from reflection, normally of order $2 \%$ (see Turner, 2005). Calculated this way, the calculated effective emissivity is more directly comparable to ground-based measurements of downwelling $I(v)$, which also implicitly incorporate both thermal emission and reflection.

Figures 4 and 5 shows micro-window $t$ (between 1038 and $1042 \mathrm{~cm}^{-1}$ ), alongside the aforementioned $\varepsilon$ pairs and their difference $\varepsilon_{b}-\varepsilon_{e}$. Values are calculated with DISORT, as a function of $r_{\mathrm{e}}$ and $\tau$, for both liquid and ice clouds.

The choice of the $\varepsilon_{b}-\varepsilon_{e}$ split-window has several strengths. First, the choice of $\varepsilon_{b}$ and $\varepsilon_{e}$ gives broad sensitivity to a wide range of values of $r_{\mathrm{e}}$ and $\tau$ for both liquid and ice clouds, although sensitivity diminishes for values of $r_{\mathrm{e}}$ larger than about $25 \mu \mathrm{m}$. For the purpose of retrievals, we can assume sensitivity for a range of parameter space bounded by a cloud transmissivity within the ozone band $t$ that is greater than 0.05 , and a cloud emissivity $\varepsilon_{b}$ at $862.5 \mathrm{~cm}^{-1}$ that is less than 0.95 and greater than 0.05 .

The second strength is that the relationship of either $r_{\mathrm{e}}$ or $\tau$ to any particular value of $\varepsilon_{b}-\varepsilon_{e}$ is comparatively insensitive to whether the cloud is assumed to be liquid or ice (Fig. 5). The mapping does not lie along a perfect 1:1 line. However, the sensitivity of the mapping to phase is small compared to other possible combinations of micro-windows. Further, errors are constrained by the incorporation of ozone band transmissivity at $1040 \mathrm{~cm}^{-1} t_{\text {ozone }}$ in the retrieval algorithm. Cloud transmissivity in the ozone band is only weakly dependent on cloud phase. Errors only exceed $(\simeq 10 \%)$ for optically thick clouds with very small particles. In any case, 

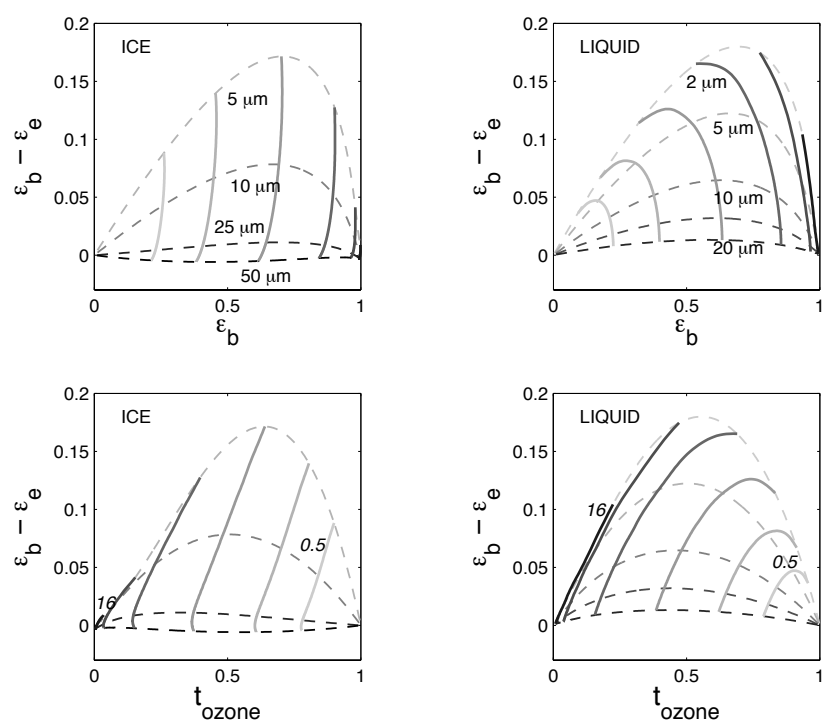

Fig. 4. "Arch plots" of split window cloud emissivity at $862.5 \mathrm{~cm}^{-1}$ $\left(\varepsilon_{b}\right)$ and $935.8 \mathrm{~cm}^{-1}\left(\varepsilon_{e}\right)$, and cloud transmittance at $1040 \mathrm{~cm}^{-1}$ $\left(t_{\text {ozone }}\right)$ for liquid and ice clouds, for a spread in effective radii $r_{\mathrm{e}}$ (dashed: as labelled) and optical depths $\tau$ (solid: 0.5, 1, 2, 4, 8, 16).
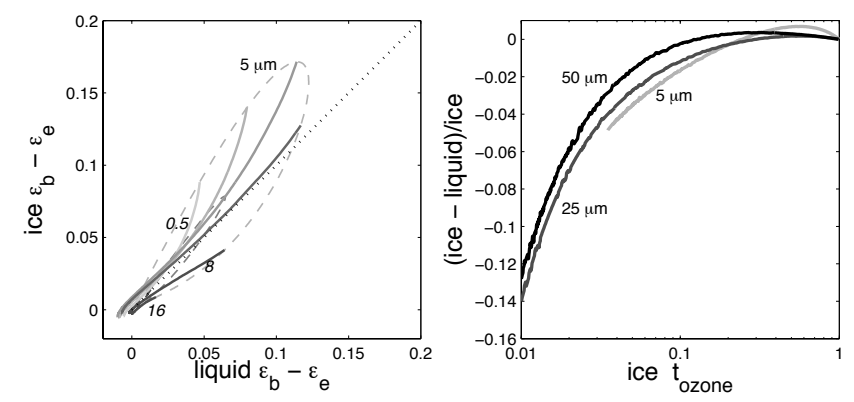

Fig. 5. Left: Range of $r_{\mathrm{e}}$ (dashed: 5 and $10 \mu \mathrm{m}$ ) and $\tau$ (solid: 0.5 , $1,2,4,8,16)$ associated with the split-window difference $\varepsilon_{b}-\varepsilon_{e}$, depending on whether a cloud is assumed to be liquid or ice. The dotted line represents 1:1 perfect correspondence. For example, a $r_{\mathrm{e}}=5 \mu \mathrm{m}$ liquid droplet in a cloud with an optical depth $\tau$ of 1 has a split-window difference that is lower than an equivalent cloud composed of ice crystals. Right: The difference in transmissivity within the ozone band associated with cloud phase assumption as a function of ozone band transmissivity $t_{\text {ozone }}$ and cloud $r_{\mathrm{e}}$.

normally such clouds can safely be assumed to be liquid. The reason for the weak dependence of transmissivity on cloud phase is that the imaginary component of the refractive index at $1040 \mathrm{~cm}^{-1}$ is close to 0.045 for both ice and water (Warren and Brandt, 2008).

\subsection{Phase determination}

Remote determination of cloud phase using infrared techniques makes use of a difference in refractive index between ice and water (e.g., Strabala et al., 1994; Turner et al., 2003;

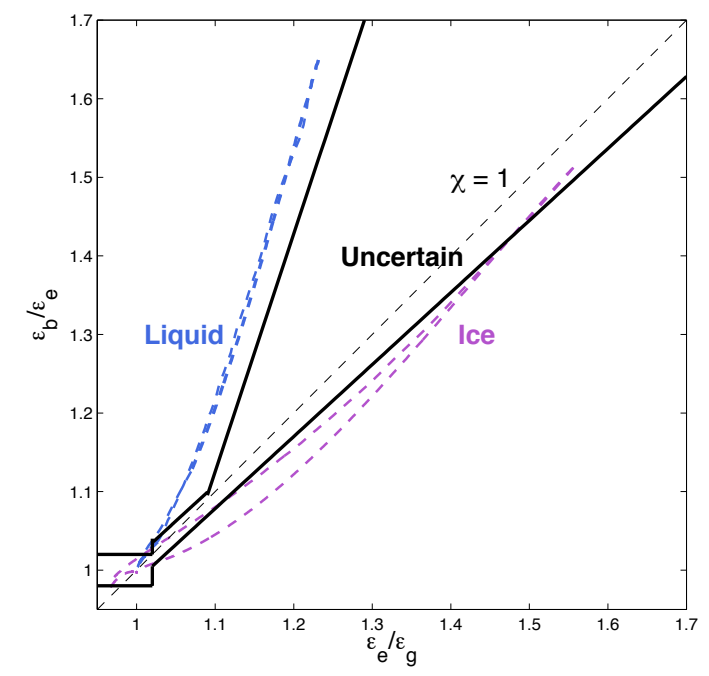

Fig. 6. An intercomparison of ratios of calculated cloud emissivities at $862.5 \mathrm{~cm}^{-1}\left(\varepsilon_{b}\right), 935.8 \mathrm{~cm}^{-1}\left(\varepsilon_{e}\right)$ and $988.4 \mathrm{~cm}^{-1}\left(\varepsilon_{g}\right)$ for assumed liquid and ice clouds. Magenta and blue dashed lines delineate these ratios for a range of plausible parameter space in $r_{\mathrm{e}}$ and $\tau$ for ice and liquid, respectively. Black lines delineate the separation between diagnosed liquid, uncertain, and ice phase retrievals. The unity ratio of the axes $\chi=1$ is shown by the dashed black line, indicating that a rough metric for ice phased clouds is that $\chi<1$.

King et al., 2004; Chylek et al., 2006; Riedi et al., 2007; Nasiri and Kahn, 2008). Strictly, what is retrieved is a cloud phase that is "radiative" rather than microphysical. For example, it is common for liquid clouds in the Arctic to contain precipitating snow crystals (Hobbs and Rangno, 1998a; Pinto et al., 2001; McFarquhar et al., 2011). Snow crystals, while larger than droplets, are found in much lower concentrations and make a near negligible contribution to the total infrared absorption cross-section density (e.g., will be shown in Fig. 7). From a radiative perspective, such clouds are purely liquid despite being microphysically "mixed-phased".

One effective approach for phase identification has been to take advantage of pronounced spectral differences between liquid and ice in the far-infrared portion of the spectrum (Turner, 2005). The disadvantage is that retrievals tend to be constrained to drier atmospheres because strong rotationalband water vapour absorption contaminates the cloud signal. Here we present in Fig. 6 a tri-spectral phase retrieval method that exploits differences in cloud emissivity within the atmospheric window, by focusing on narrow microwindows where water vapour absorption is particularly small (Fig. 3). We have found that micro-windows at $862.5 \mathrm{~cm}^{-1}$ $\left(\varepsilon_{b}\right), 935.8 \mathrm{~cm}^{-1}\left(\varepsilon_{e}\right)$ and $988.4 \mathrm{~cm}^{-1}\left(\varepsilon_{g}\right)$ can be paired to neatly separate cloud phase for much of the plausible space in $\left(r_{e}, \tau\right)$. Figure 6 shows that a full range of plausible parameter space in $r_{\mathrm{e}}$ and $\tau$ for ice and liquids lies neatly along two distinct lines in a space of $\varepsilon_{b} / \varepsilon_{e}$ and $\varepsilon_{e} / \varepsilon_{g}$. This suggests that, roughly, where measurements of the ratio 


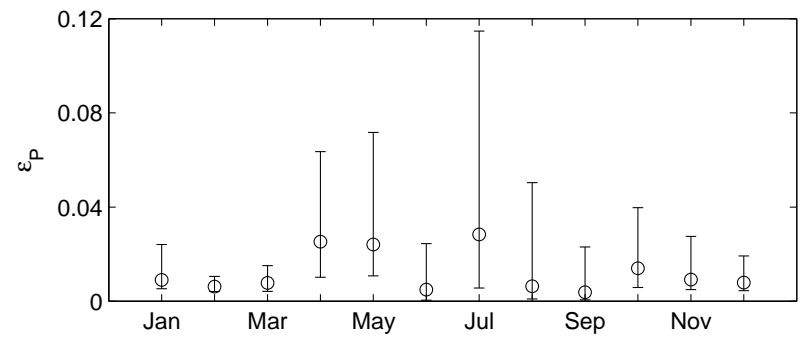

Fig. 7. Seasonal variation in retrieved precipitation emissivity at $934.5 \mathrm{~cm}^{-1}$ obtained at NSA-AAO between 2000 and 2003. Points are median values and bars the limits of the upper and lower quartiles.

$\chi=\left(\varepsilon_{b} / \varepsilon_{e}\right) /\left(\varepsilon_{e} / \varepsilon_{g}\right)$ are greater than unity, the cloud can be identified as being liquid. The opposite is true for ice clouds.

Clouds that are more spectrally flat, or in between ice and liquid, are not amenable to phase discrimination and are labelled "uncertain". In reality, many of these cases may in fact be "mixed-phased". However, the ambiguity in the retrieval prohibits us from identifying such clouds with certainty. Nonetheless, as will be shown, retrievals of cloud properties are relatively insensitive to an a priori assessment of cloud phase, so retrievals of cloud properties are still performed where possible.

\subsection{Estimation of cloud emissivity from measurements}

In principle, cloud emissivity can be calculated from Eq. 1 using ground-based radiometer measurements of downwelling spectral radiance $I_{\text {meas }}(v)$ combined with some estimate of cloud temperature. This works, provided that there is negligible emission by atmospheric constituents between the cloud and the ground.

We have chosen micro-windows where emission and absorption of radiation by atmospheric gases is particularly small. However, cases can exist where below-cloud hydrometeors contribute non-negligibly to downwelling thermal radiance. To address this possibility, we first estimate a characteristic precipitation particle radius and number concentration using a precipitation retrieval method we previously developed in Zhao and Garrett (2008). This technique retrieves precipitation microphysical properties as a function of radar reflectivity and Doppler velocity. The absorption $\left(Q_{\mathrm{abs}, \mathrm{P}}(v)\right)$ and extinction $\left(Q_{\text {ext, } \mathrm{P}}(v)\right)$ coefficients for precipitation can be computed from Mie theory (Wiscombe, 1980) based on the retrieved precipitation particle radius $(r)$ and precipitation phase. From these values, precipitation spectral emissivity $\left(\varepsilon_{P}(v)\right)$ can be determined from

$$
\varepsilon_{P}(v)=1-\exp \left(-\int_{\Delta z} \pi Q_{\mathrm{ext}, \mathrm{P}}(v) N r^{2} d z\right)
$$

where $N$ is the precipitation particle concentration, and $\Delta z$ is the depth of the precipitation layer.

For greatest precision, the below cloud contribution to downwelling radiance from water vapour could also be included. In this case, the corresponding emissivity $\varepsilon_{v}(v)$, could in principle be calculated from Eq. 1 using a Line by Line Radiative Transfer Model (LBLRTM; Clough et al., 1992) based on measured ozone, temperature, and moisture profiles. Noting that transmittances multiply, the total emissivity of water vapour and precipitation $\varepsilon_{v} P$ would be

$\varepsilon_{v P}=\varepsilon_{v}+\left(1-\varepsilon_{v}\right) \varepsilon_{P}$

in which case, ignoring the second-order term in $\varepsilon_{v} \varepsilon_{P}$, the corrected form of Eq. 1 for cloud emissivity is

$\varepsilon(v)=\frac{I_{\text {meas }}(v)-\varepsilon_{v P}(v) B\left(T_{P}, v\right)}{\left(1-\varepsilon_{v P}\right) B\left(T_{\mathrm{C}}, v\right)}$

where $I_{\text {meas }}(v)$ is the surface measured radiation at wavenumber $v$, and $B\left(T_{P}, v\right)$ and $B\left(T_{\mathrm{C}}, v\right)$ represent blackbody radiation at $v$ for mean precipitation and cloud temperature $T_{P}$ and $T_{\mathrm{C}}$; temperatures are estimated by matching detected heights to measured atmospheric temperature soundings. Here, for the sake of retrieval simplicity we make the approximation that $\varepsilon_{v} \simeq \varepsilon_{P}$. The associated error from making this approximation is discussed in the appendix.

With the contribution of precipitation to thermal emission excluded, the contribution of clouds and other trace gases to downwelling surface radiance is

$I_{C}(v)=\varepsilon(v) B\left(T_{\mathrm{C}}, v\right)$

Figure 7 shows values of $\varepsilon_{P}$ obtained near Barrow, Alaska based on precipitation properties derived by Zhao and Garrett (2008). Retrieved values of $\varepsilon_{P}$ range from 0 to 0.14 with lower and upper quartile values of 0.01 and 0.04 , respectively. Because values of $\varepsilon_{P}$ are generally low, the combined contribution of water vapour and precipitation to $I_{c}$ is typically about $1 \%$, in which case it can usually be ignored for the purpose of retrieving cloud properties. However, in the upper quartile, precipitation has a thermal emissivity greater than 0.05 , and contributes in excess of $3 \%$ to $I_{\text {sky }}$. Therefore, if a higher certainty of accuracy is desired, thermally based cloud retrievals should systematically account for the precipitation radiation contribution.

\subsection{Estimation of cloud transmissivity from measurements}

In order to constrain estimates of cloud emissivity, it helps to have an estimate of cloud transmissivity $t$ since, to first order, $\varepsilon=1-t$. Cloud transmissivity is often estimated using the sun as a direct source. The drawback is that the sun can be absent for long stretches of time in the Arctic.

Here we estimate cloud transmissivity from the degree to which a cloud attenuates downwelling atmospheric ozone 

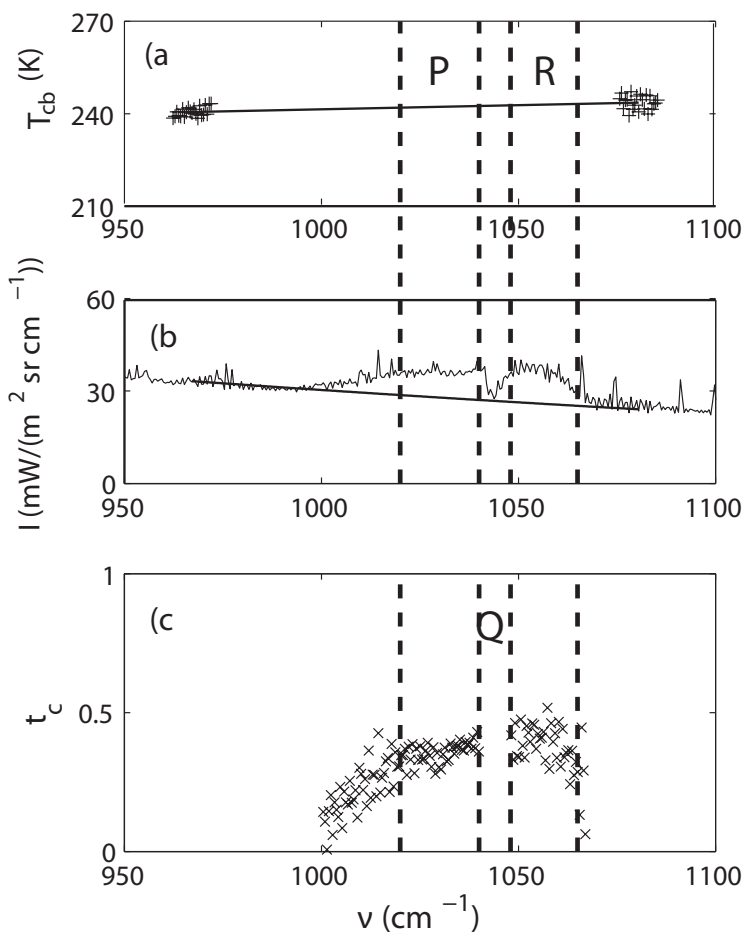

Fig. 8. The steps used to determine cloud transmittance of ozone downwelling emission in a $1038-1042 \mathrm{~cm}^{-1}$ micro-window. (Top): The brightness temperature $T_{\mathrm{cb}}$ at cloud base is calculated on both sides of the ozone emission band, at $970-990 \mathrm{~cm}^{-1}$ and 1070 $\left.1100 \mathrm{~cm}^{-1}\right)$. Then, the cloud brightness temperature $T_{\mathrm{cb}}$ within the $\mathrm{P}$ and $\mathrm{R}$ branches of the ozone band is obtained using linear interpolation. (Middle): The background radiance $I_{\mathrm{bkg}}$ from non-ozone sources is calculated from the estimated cloud brightness temperatures. (Bottom): The transmissivity $t$ in the $\mathrm{P}$ and $\mathrm{R}$ branches of the ozone band is calculated from the measured downwelling radiance $I_{\text {sky }}$ (corrected for precipitation contributions) from $t=\left(I_{\text {sky }}-I_{\mathrm{bkg}}\right) / I_{\text {clear }}$, where $I_{\text {clear }}$ is the clear sky downwelling radiance estimated from ozone, temperature and moisture profiles. Transmissivity values within the central $\mathrm{Q}$ branch between $1040 \mathrm{~cm}^{-1}$ and $1048 \mathrm{~cm}^{-1}$ are estimated by interpolating between the two regions delimited by dashed lines. Values of $t_{\text {ozone }}$ are derived from a subset of transmissivity values within a $1038-1042 \mathrm{~cm}^{-1}$ micro-window where water vapour absorption is small. The data shown is from measurements at ARM NSA-AAO on 15 July 2000.

emission within a $1038 \mathrm{~cm}^{-1}$ to $1042 \mathrm{~cm}^{-1}$ micro-window. Because ground based measurements of downwelling radiation include both cloud and precipitation emission and ozone transmission, cloud and precipitation emission must first be subtracted to obtain the ozone signal. Transmissivity can then be obtained if atmospheric ozone, temperature and moisture profiles are known. The ozone signal is isolated by examining transmissivity within a narrow micro-window for water vapor emission is small.

The procedure for estimating cloud transmissivity within the $1038 \mathrm{~cm}^{-1}$ to $1042 \mathrm{~cm}^{-1}$ micro-window follows a series of steps illustrated in Fig. 8. In the first step, surface radiance measurements $I_{\text {meas }}(v)$ are corrected for precipitation emission to give

$I_{\text {sky }}(v)=I_{\text {meas }}(v)-\varepsilon_{P}(v) B\left(T_{P}, v\right)$

In the second step, a wavelength dependent brightness temperature $T_{\mathrm{cb}}$ representative of cloud base is estimated from the relation $I_{\mathrm{sky}}(v)=B\left(T_{\mathrm{cb}}, v\right)$. Intensity measurements are evaluated in two ranges, between $960 \mathrm{~cm}^{-1}$ and $975 \mathrm{~cm}^{-1}$ and between $1070 \mathrm{~cm}^{-1}$ and $1085 \mathrm{~cm}^{-1}$. These spectral bands lie within the atmospheric window, but just outside the $\mathrm{P}$ and $\mathrm{R}$ branches of ozone emission.

In the third step, the prior estimates of brightness temperature from outside the ozone band are used to evaluate values of $T_{\mathrm{cb}}$ within the $\mathrm{P}$ and $\mathrm{R}$ branches associated with ozone emission. This is done using simple linear interpolation. This calculated value of $T_{\mathrm{cb}}$ within the ozone band is used to estimate the background radiance $I_{\mathrm{bkg}}(v)$ that comes from all other sources than ozone and precipitation, including clouds, water vapour and other greenhouse gases.

Fourth, cloud transmissivity $t$ is calculated within the $\mathrm{P}$ and $\mathrm{R}$ branches of ozone emission. The calculated background emission $I_{\mathrm{bkg}}$ is subtracted from measurements of downwelling emission $I_{\text {sky }}$ within the $\mathrm{P}$ and $\mathrm{R}$ branches. The difference is divided by calculated values of the clear sky downwelling radiance $I_{\text {clear }}$ in the $\mathrm{P}$ and $\mathrm{R}$ branches that would be associated with an atmosphere without precipitation or clouds

$t(v)=I_{\text {cloudy }}(v) / I_{\text {clear }}(v)=\left(I_{\text {sky }}(v)-I_{\text {bkg }}(v)\right) / I_{\text {clear }}(v)$

Values of $I_{\text {clear }}$ are estimated using the LBLRTM radiative transfer model and measured profiles of atmospheric ozone, temperature and moisture.

Fifth, values of $t$ that are calculated in two narrower spectral bands $-1020 \mathrm{~cm}^{-1}$ to $1040 \mathrm{~cm}^{-1}$ in the $\mathrm{P}$ branch and $1048 \mathrm{~cm}^{-1}$ to $1065 \mathrm{~cm}^{-1}$ in the $\mathrm{R}$ branch - are then used to interpolate values of $t$ in the Q branch between $1040 \mathrm{~cm}^{-1}$ and $1048 \mathrm{~cm}^{-1}$, thereby completing estimates of $t$ within the ozone band. Interpolation is used because ozone emission is weak within the Q branch.

Finally, the desired values of $t_{\text {ozone }}$ are obtained from a subset of these ozone transmissivity values, evaluated within a micro-window between $1038 \mathrm{~cm}^{-1}$ and $1042 \mathrm{~cm}^{-1}$. This micro-window is chosen because water vapour absorption is particularly small in this band.

\subsection{Retrieval of cloud properties}

Cloud effective radius $\left(r_{\mathrm{e}}\right)$ and visible optical depth $(\tau)$ can now be obtained in a two step process. First observed values of $\varepsilon_{b}, \varepsilon_{e}$ and $\varepsilon_{g}$ are calculated from measured downwelling radiances, corrected for below cloud atmospheric emission from precipitation particles. These are then used to identify cloud phase using the described tri-spectral retrieval method. 
Then, the observed values of $\varepsilon_{b}$ and $\varepsilon_{e}$, along with observed values of $t$ in the ozone band micro-window, are compared to those in a look-up table for $r_{\mathrm{e}}$ and $\tau$ for either ice or liquid clouds. Calculations are a simple least-squares minimisation of

$\left|\left[\varepsilon_{b}, \Delta \varepsilon, t\right]_{\text {observations }}-\left[\varepsilon_{b}, \Delta \varepsilon, t\right]_{\text {calculations }}\right|$

where, $\Delta \varepsilon=\varepsilon_{b}-\varepsilon_{e}$.

The variables in the minimisation algorithm are weighted according to the relative magnitudes of their uncertainties. Uncertainties in $\varepsilon$ result mostly from uncertainties in estimates of cloud-base temperature and uncertainties in measurements of downwelling spectral radiance, due for example to water vapour emission. In the latter case, these uncertainties are expected to manifest themselves as a bias. Values of $\Delta \varepsilon$, on the other hand, are highly robust to errors in temperature estimates, so they are weighted five times higher than emissivity $\varepsilon_{b}$. Cloud transmittance $(t)$ is weighted three times higher than $\varepsilon_{b}$ because it is comparatively insensitive to uncertainties in estimated cloud phase. For clouds with an uncertain phase, retrievals of cloud properties are made assuming that the clouds are liquid. The assumption is that many "uncertain" clouds are in fact mixed-phased, in which case most of the cloud water path (and thermal emission) comes from high concentrations of small liquid droplets (Hobbs and Rangno, 1998b). In any case, as will be shown, retrievals tend not to be highly sensitive to this choice.

By assuming a log-normal cloud particle size distribution, such cloud properties as water path WP and particle number concentration $N$, are related to retrieved $r_{\mathrm{e}}$ and $\tau$ through

$W P=2 \rho r_{e} \tau / 3$

$N=3 \exp \left(3 \sigma^{2}\right) \mathrm{WP} /\left(4 \pi \rho r_{e}^{3} \Delta H\right)$

where $\rho$ is the water or ice density depending on the phase, $\sigma$ the assumed standard log-normal deviation of the particle size distribution, and $\Delta H=H_{\mathrm{top}}-H_{\text {base }}$ is the difference between the measured cloud-top and -base heights.

We estimate a suitable value for $\sigma$ of $0.32 \pm 0.10$ based on a reanalysis of airborne measurements of particle size distributions $<50 \mu \mathrm{m}$ diameter obtained with an FSSP-100 during four University of Washington field campaigns in the Arctic between 1982 and 1998 (Garrett et al., 2004). It is more difficult to obtain a representative value for ice clouds, in part due to concerns about aircraft instrument performance (Field et al., 2003), but the value of $\sigma$ is not necessarily markedly different (e.g., Rangno and Hobbs, 2001, Fig. 8). Accordingly, $\sigma$ for ice and liquid are assumed to be identical, but with an uncertainty for ice that is twice as large, i.e., $\sigma=0.32 \pm 0.20$.

Generally it is accepted that saturation effects limit infrared retrieval techniques to values of WP lower than about
$40 \mathrm{~g} \mathrm{~m}^{-2}$ (Garrett et al., 2002), but this is not always the case. The imaginary component of the refractive index is 0.046 for both ice and water in the portion of the ozone transmission band between $1038 \mathrm{~cm}^{-1}$ and $1042 \mathrm{~cm}^{-1}$ (Warren, 1984; Wieliczka et al., 1989). Therefore, in a bulk water medium, an ozone band transmittance value of 0.05 , which is the lower sensitivity cutoff in the infrared retrieval technique used here, should correspond to a liquid water absorption path of $60 \mathrm{~g} \mathrm{~m}^{-2}$. Sensitivity to liquid water path can even extend beyond $60 \mathrm{~g} \mathrm{~m}^{-2}$ if cloud particle radii are larger than about $10 \mu \mathrm{m}$ (Fig. 4). The reason is that the skin depth for droplet absorption is smaller than the droplet radius itself. Any incident radiation is absorbed almost completely by the droplet exterior such that the interior is effectively invisible to the incident infrared radiation. The consequence is that the water path of a cloud can be higher before the cloud approximates a blackbody.

\section{Measurements}

The datasets used in this study are from the DOE Atmospheric Radiation Measurement (ARM) Programme North Slope of Alaska - Adjacent Arctic Ocean (NSA-AAO) site, the NOAA Global Monitoring Division (GMD), the European Remote Sensing satellite (ERS) Global Ozone Monitoring Experiment (GOME), the European Centre for Medium-Range Weather Forecasts (ECMWF), and the National Weather Service (NWS). The period of data acquisition is 2000 to 2003 to be consistent with analysis described in Garrett and Zhao (2006). For analysis, measurements were grouped into five minute intervals. All ground-based data used here were obtained near Barrow, Alaska. Table 1 summarises the measurement site, instruments, resolution and accuracy.

\section{Cloud Remote Sensing Measurements}

Cloud properties were measured using a combination of active and passive remote sensors. Key instruments used for cloud retrievals from NSA-AAO include the Vaisala 25K Laser Ceilometer, the Micropulse Lidar, the Atmospheric Emitted Radiance Interferometer (AERI), and the millimetre wavelength cloud radar (MMCR) (Peppler et al., 2008).

The Atmospheric Emitted Radiance Interferometer (AERI) is an automated ground-based passive interferometer, which measures downwelling atmospheric radiance spectra within a $1.3^{\circ}$ field-of-view. The spectral range the AERI covers is between 400 and $3300 \mathrm{~cm}^{-1}$ with a spectral resolution of approximately $1 \mathrm{~cm}^{-1}$. The radiometric accuracy of AERI instruments (for 3 standard deviations) is better than $1 \%$ of ambient radiance (Knuteson et al., 2004). For the atmospheric window measurements used here to detect cold arctic 
clouds this corresponds to uncertainties better than $0.5 \mathrm{~mW} /\left(\mathrm{m}^{2} \mathrm{srcm}^{-1}\right)$.

A Vaisala Laser Ceilometer is used to determine cloud base, separate from precipitation, from sharp gradients in backscatter, and with an uncertainty of $7.6 \mathrm{~m}$ (Dong et al., 2005). Since its accuracy diminishes with height (Jay Mace personal communication), retrievals are restricted here to clouds with bases less than $4000 \mathrm{~m}$ altitude. The micropulse lidar (MPL) provides cloud boundaries with a height resolution of $30 \mathrm{~m}$ (Campbell et al., 2002). Where the MPL is attenuated, the Millimetre-wave Cloud Radar (MMCR) provides profiles of radar reflectivity with measurement uncertainties of $0.5 \mathrm{~dB}$. MMCR estimates of cloud boundaries have an accuracy of $45 \mathrm{~m}$ (Dong and Mace, 2003a). Here the MPL and MMCR are also used to exclude cases with multiple cloud layers (for example cirrus over stratus). More complicated scenes with multilayered liquid clouds and ice crystal precipitation filling the vertical space between layers are interpreted as single layer clouds.

We found that the ceilometer occasionally detects the base of a thin cloud that is invisible to the radar; or, if the cloud precipitates, the radar cloud top lies below the ceilometer cloud base. When this occurs, retrievals of cloud thickness and, hence, number concentration $N$ are impossible or nonsensical. However, estimates of other cloud properties are still performed since they do not rely on cloud thickness measurements.

For the purpose of a later comparison with the proposed thermal retrieval method, values of column-integrated liquid water path (LWP) are derived from brightness temperatures measured with a microwave radiometer (MWR) (Liljegren et al., 2001). The root-mean-square uncertainties of the LWP retrievals are commonly between $10 \mathrm{~g} \mathrm{~m}^{-2}$ and $15 \mathrm{~g} \mathrm{~m}^{-2}$, but can be higher than $30 \mathrm{~g} \mathrm{~m}^{-2}$ (Marchand et al., 2003).

2. Atmospheric Ozone, Temperature and Moisture

Calculation of cloudy transmission $t$ of ozone emission requires profiles of atmospheric ozone, temperature and moisture. Surface ozone concentrations are provided from ultraviolet ozone photometers at the GMD site at Barrow, Alaska. Stratospheric ozone profiles $(>6 \mathrm{~km})$ are the assimilated ERS-GOME 3-D ozone distributions from the World Data Center for Remote Sensing of the Atmosphere, WDC-RSAT (?). Ozone profiles from the surface to $6 \mathrm{~km}$ are obtained by interpolating between GOME stratospheric ozone profiles and GMD surface ozone measurements assuming a standard seasonal ozone profile. The time resolution for ozone profile measurements is $6 \mathrm{~h}$ and hourly at the surface. The accuracy of satellite measured profiles of stratospheric ozone concentration is about $5-10 \%(\sim 100 \mathrm{ppb})(\mathrm{La}-$ paolo et al., 2007), and the accuracy of surface ozone concentration measurements from GMD is about $2 \%$.

Temperature and moisture profiles are obtained from twice-daily NWS balloon-borne profiles up to the maximum measured altitude - typically about $16 \mathrm{~km}$. Above that level, European Center for Medium range Weather Forecasting (ECMWF) ERA-40 reanalyses are used (Uppala et al., 2005). Above $60 \mathrm{~km}$, temperatures and humidities are fixed to $230 \mathrm{~K}$ and 5 ppmv. For times intermediate to the NWS profile intervals, a temporal linear interpolation is applied to the data. For heights intermediate to measured profile levels, cloud base and cloud top temperatures are obtained by applying a vertical linear interpolation. For the purpose of retrievals, we assume that balloon-sonde tropospheric water vapour measurements have an uncertainty of $15 \%$ and that the measured upper-level temperature profiles have an uncertainty of $5 \%$, or roughly $\pm 12 \mathrm{~K}$.

In the troposphere, temperature profiles are important for assessing cloud temperature. Based on observed temperature variability during the diurnal cycle, uncertainties in cloud base and cloud top temperatures are estimated to be $\pm 3 \mathrm{~K}$. Other trace gases, such as carbon dioxide $\left(\mathrm{CO}_{2}\right)$ and methane $\left(\mathrm{CH}_{4}\right)$ do not have primary absorption bands at the frequencies used here. Associated uncertainties in cloud property retrievals are less than $1 \%$ and are not considered in detail.

\section{Error analysis}

Sources of uncertainty in retrievals come from both the measurements and the retrieval technique itself. To calculate the magnitude of the errors that are specific to the retrieval technique, the technique is tested on synthetically created clouds. These errors are then combined with errors in the technique associated with measurement uncertainties. The intent here is to evaluate the extent to which adequate physics was implemented correctly in the algorithm development.

We test the ability of the retrieval technique to accurately infer synthetically specified values of cloud properties. Downwelling spectral radiance $(I)$ at the surface is calculated using DISORT based on synthetically specified values of $r_{\mathrm{e}}$, $\tau, H_{\text {base }}, H_{\text {top }}$ and cloud temperature. From the values of $I$, the cloud properties $r_{\mathrm{e}}$ and $\tau$ are "retrieved" and compared with the synthetic values.

In this test, specified values of $\tau$ and $r_{\mathrm{e}}$ range from 0.1 to 16.0, and from $3.0 \mu \mathrm{m}$ to $50.0 \mu \mathrm{m}$, respectively. Cloud base and cloud top height and temperature are set to $223 \mathrm{~m}$ and $438 \mathrm{~m}$, and $260 \mathrm{~K}$ and $256 \mathrm{~K}$, respectively. Ozone $\left(\mathrm{O}_{3}\right)$, temperature $(T)$ and water vapour (WV) profiles $\left(\mathrm{O}_{3}\right.$ and $T$ profiles are shown in Fig. 9), are subjectively chosen from measurements at ARM NSA-AAO obtained on 7 May 2000 and 15 January 2001. 
Figure 10 shows that "retrieved" cloud properties agree very well with the synthetic values. Errors associated with retrievals of $\tau$ are not shown since they are $<2 \%$ throughout the parameter space in $r_{\mathrm{e}}$ and $\tau$. For $r_{\mathrm{e}}$, LWP, and $N$, computed values of $95 \%$ confidence retrieval errors associated with the method exceed $10 \%$ only where values of $r_{\mathrm{e}}$ exceed $30 \mu \mathrm{m}$ and values of $\tau$ exceed about 6 , presumably because $Q_{\text {abs }}$ is only a weak function of $r_{\mathrm{e}}$ and the sensitivity of cloud emissivity to $\tau$ decreases as a cloud thickens to approximate a blackbody. That we have assumed that clouds are microphysically homogeneous in the vertical may mean that additional errors are associated with true clouds. Retrievals based on cloud transmissivity of downwelling atmospheric radiation will tend to be biased by the microphysics at cloud top since this is near where radiative attenuation is a maximum; retrievals based on cloud thermal emission will be biased by properties at cloud base. Because the retrievals here are based on both emission and transmission, derived properties are expected to represent some radiative average of the vertical profile.

The primary uncertainties in the retrievals arise from measurement errors. Based on the discussion of measurement accuracies in Sect. 3, the $95 \%$ confidence uncertainties in cloud base temperature $\left(T_{\mathrm{c}}\right)$, AERI radiance $(I)$, water vapour profile $\left(\mathrm{H}_{2} \mathrm{O}\right)$, ozone profile $\left(\mathrm{O}_{3}\right)$ and cloud depth $(\Delta H)$ are estimated to be about $\pm 3 \mathrm{~K}, 0.5 \mathrm{~mW} /\left(\mathrm{m}^{2} \mathrm{sr} \mathrm{cm}^{-1}\right), 15 \%$, $100 \mathrm{ppb}$, and $50 \mathrm{~m}$, respectively. Uncertainties in stratospheric temperature and moisture profiles are $5 \%$. Aircraft measurements from the FIRE-ACE field campaigns show uncertainty in the cloud particle log-normal distribution spectral width $(\sigma)$ to be \pm 0.10 for liquid clouds (Garrett et al., 2004), and it is assumed to be \pm 0.20 for ice clouds.

Assuming that errors from measurements of $T_{\mathrm{c}}, \mathrm{I}, \mathrm{O}_{3}$, $\Delta H$ and $\sigma$ are independent, the 1-sigma retrieval error in property $x$ due to combined measurement and retrieval method errors is

$\sigma_{x}^{2}=\sigma_{M}^{2}\left(\frac{\partial x}{\partial M}\right)^{2}+\sigma_{I}^{2}\left(\frac{\partial x}{\partial I}\right)^{2}+\sigma_{H_{2} \mathrm{O}}^{2}\left(\frac{\partial x}{\partial \mathrm{H}_{2} \mathrm{O}}\right)^{2}+\sigma_{\mathrm{O}_{3}}^{2}\left(\frac{\partial x}{\partial \mathrm{O}_{3}}\right)^{2}$

$+\sigma_{T}^{2}\left(\frac{\partial x}{\partial T}\right)^{2}+\sigma_{\Delta h}^{2}\left(\frac{\partial x}{\partial \Delta \mathrm{H}}\right)^{2}+\sigma_{\sigma}^{2}\left(\frac{\partial x}{\partial \sigma}\right)^{2}$

where $\sigma_{y}$ is the standard deviation of variable $y, M$ represents the retrieval method, and $I, \mathrm{H}_{2} \mathrm{O}, \mathrm{O}_{3}, T, \Delta H$ and $\sigma$ are measurement variables, the brackets () contain the sensitivity of $x$ to the measurements or retrieval method. Here, the covariance between the different quantities is assumed to be zero because the measurements are independent.

Table 2 shows estimates of the liquid and ice cloud retrieval errors due to combined uncertainties in the retrieval method and measurements. The errors in $r_{\mathrm{e}}, \tau$, and WP are due mainly to uncertainties in cloud base temperature and AERI radiance. Errors in $N$ are also strongly dependent on uncertainties in cloud depth and the standard deviation of the droplet or ice size distribution. The combined $95 \%$ confidence uncertainties in cloud $r_{\mathrm{e}}, \tau$, and WP are about $10 \%$,
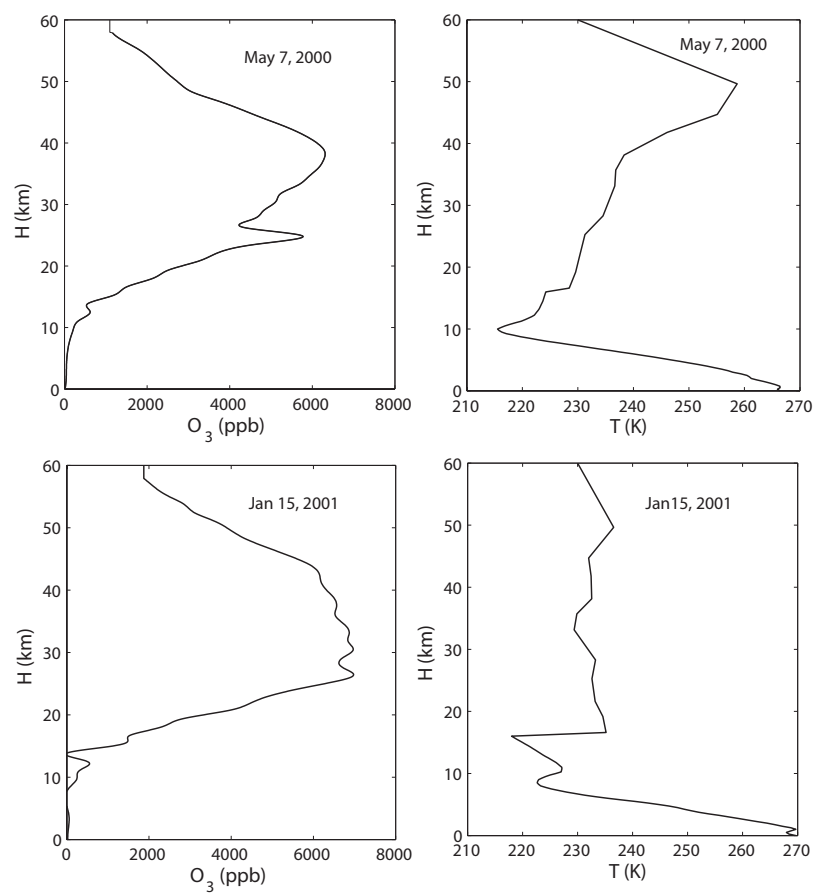

Fig. 9. Ozone (left) and temperature (right) profiles at Barrow, Alaska, obtained on 7 May 2000 (above) and 15 January 2001 (below).

$20 \%$, and $16 \%$. For $N$, they are $38 \%$ and $55 \%$ for liquid and ice, respectively.

\section{Evaluation}

\subsection{Comparison with measurements}

Using the phase identification method employed here, it was possible to identify whether the cloud phase was liquid or ice in $65 \%$ of cases where there were thin clouds with $0.05<\varepsilon_{b}<0.95$. The remainder of cases were classified as having an uncertain phase. One way to assess the magnitude of error in the cloud phase determination is to examine the detected phase above and below certain known phase transitions, such as the melting and homogeneous freezing points. For thin cloud cases with cloud top temperatures higher than $273 \mathrm{~K}$, clouds were classified as being ice in $6 \%$ of cases and liquid in $45 \%$ of cases, the remainder being uncertain. The respective numbers for clouds with base temperatures below $238 \mathrm{~K}$ were $73 \%$ and $11 \%$. These numbers suggest that, in about $10 \%$ of cases where a phase identification was made, the phase was misclassified.

A second approach for evaluating the phase retrievals is to compare with ARM Microwave Radiometer (MWR) measurements. The MWR is insensitive to ice so, in principle, it should not detect water when the infrared method identifies an ice cloud. Fig. 11 shows a comparison between retrieved 
Table 1. Site, instrument, resolution, and $95 \%$ confidence accuracy of measurements used in this study.

\begin{tabular}{lcccc}
\hline Source & Instrument & Data & resolution & Accuracy \\
\hline ERS- & Satellite & & & \\
GOME & Spectrometer & Stratospheric O 3 profile & $6 \mathrm{~h}$ & $5-10 \%$ \\
GMD & Photometers & Surface ozone & $1 \mathrm{~h}$ & $2 \%$ \\
NWS & Rawinsonde & Temperature Profile & $12 \mathrm{~h}$ & $3 \mathrm{~K}$ \\
NWS & Rawinsonde & Water vapor Profile & $12 \mathrm{~h}$ & $15 \%$ \\
ECMWF & Simulation & Temperature Profile & $6 \mathrm{~h}$ & $3 \mathrm{~K}$ \\
ECMWF & Simulation & Water vapor Profile & $6 \mathrm{~h}$ & $15 \%$ \\
ARM & AERI & Surface Radiation & $450 \mathrm{~s}$ & $0.5 \mathrm{~mW}^{2}\left(\mathrm{~m}^{2} \mathrm{sr} \mathrm{cm}^{-1}\right)$ \\
ARM & Laser/Ceilometer & Cloud Base & $36 \mathrm{~s}$ & $7.6 \mathrm{~m}$ \\
ARM & MMCR Radar & Radar Reflectivity & $36 \mathrm{~s}$ & $0.5 \mathrm{~dB}^{-1}$ \\
ARM & MMCR Radar & Cloud Top & $36 \mathrm{~s}$ & $45 \mathrm{~m}^{-1}$ \\
ARM & MMCR Radar & Doppler velocity & $36 \mathrm{~s}$ & $0.1 \mathrm{~m} \mathrm{~s}^{-1}$ \\
ARM & MWR & Liquid water path & $15 \mathrm{~s}$ & $30 \mathrm{~g} \mathrm{~m}^{-2}$ \\
\hline
\end{tabular}

Table 2. Typical $95 \%$ confidence retrieval errors for liquid and (ice) cloud $r_{\mathrm{e}}, \tau$, WP and $N$ based on combined measurement and retrieval errors.

\begin{tabular}{lccccc}
\hline & Measurement & $r_{\mathrm{e}}$ & $\tau$ & $\mathrm{WP}$ & $N$ \\
\hline$T_{\mathrm{c}}$ & $\sim 3 \mathrm{~K}$ & $8 \%$ & $15 \%$ & $12 \%$ & $21 \%$ \\
$T$ profile & $5 \%$ & $1 \%$ & $7 \%$ & $6 \%$ & $7 \%$ \\
$\mathrm{H}_{2} \mathrm{O}$ vapour profile & $15 \%$ & $1 \%$ & $1 \%$ & $1 \%$ & $3 \%$ \\
$I$ & $\sim 0.5 \mathrm{~mW} /\left(\mathrm{m}^{2} \mathrm{srcm}^{-1}\right)$ & $5 \%$ & $10 \%$ & $8 \%$ & $10 \%$ \\
$\Delta H$ & $\sim 50 \mathrm{~m} \mathrm{(} 20 \%)^{20}$ & & & & $20 \%$ \\
$\mathrm{O}_{3}$ & $\sim 100 \mathrm{ppb}$ & $1 \%$ & $1 \%$ & $1 \%$ & $3 \%$ \\
$\sigma$ & \pm 0.10 & & & & $20(45) \%$ \\
Method & & $1 \%$ & $1 \%$ & $2 \%$ & $2 \%$ \\
Total & & $10 \%$ & $20 \%$ & $16 \%$ & $38(55) \%$ \\
\hline
\end{tabular}

values of LWP and IWP using the infrared-based method and the LWP derived from the MWR, evaluated for all cases where comparisons were possible. What is shown is a fairly high correlation $\left(r^{2}=0.50\right)$ between microwave and thermal IR retrievals of LWP, but with a $10 \mathrm{~g} \mathrm{~m}^{-2}$ to $15 \mathrm{~g} \mathrm{~m}^{-2}$ positive bias in the MWR LWP measurements, consistent with known uncertainties in the MWR retrievals (Marchand et al., 2003). By comparison, thermal retrievals of IWP and the MWR LWP do not correlate well $\left(r^{2}=0.06\right)$. When the infrared based retrievals of IWP are non-zero, the MWR LWP retrievals are consistently within MWR uncertainty bounds.

For those cases where the retrieved cloud phase is "uncertain", it may nonetheless be possible to retrieve cloud optical depth $\tau$ and effective radius $r_{\mathrm{e}}$ to within an acceptable degree of confidence. Figure 12 shows a comparison between the values of retrieved $\tau$ and $r_{\mathrm{e}}$ for "uncertain" cases depending on whether the cloud optical properties are treated as being either liquid or ice. For example, if the cloud were composed of ice, but the cloud microphysics were calculated as if it were liquid, then the optical depth would be overestimated, and the effective radius would be underestimated, by about $15 \%$. These additional uncertainties are comparable to those due to measurement errors where the cloud phase has been correctly determined (Table 2).

\subsection{Comparison with independent retrievals}

The final comparison is between the infrared-based retrieval approach described here and an independent retrieval approach that has been applied to the same time period and location by Dong and Mace (2003b). The Dong and Mace method is based on ground pyrometer measurements of solar shortwave cloud transmissivity and MWR retrievals of liquid water path. Combined with the solar zenith angle and measurements of surface albedo, Dong and Mace applied their technique to retrieve liquid cloud optical depth, cloud droplet effective radius, and cloud droplet number concentration.

The infrared method described here begins to saturate for liquid water paths greater than $40 \mathrm{~g} \mathrm{~m}^{-2}$ whereas the Dong and Mace method, being based on MWR measurements, is less well suited for liquid water paths below $40 \mathrm{~g} \mathrm{~m}^{-2}$. This means that the two methods could ultimately be used in a complementary fashion. 

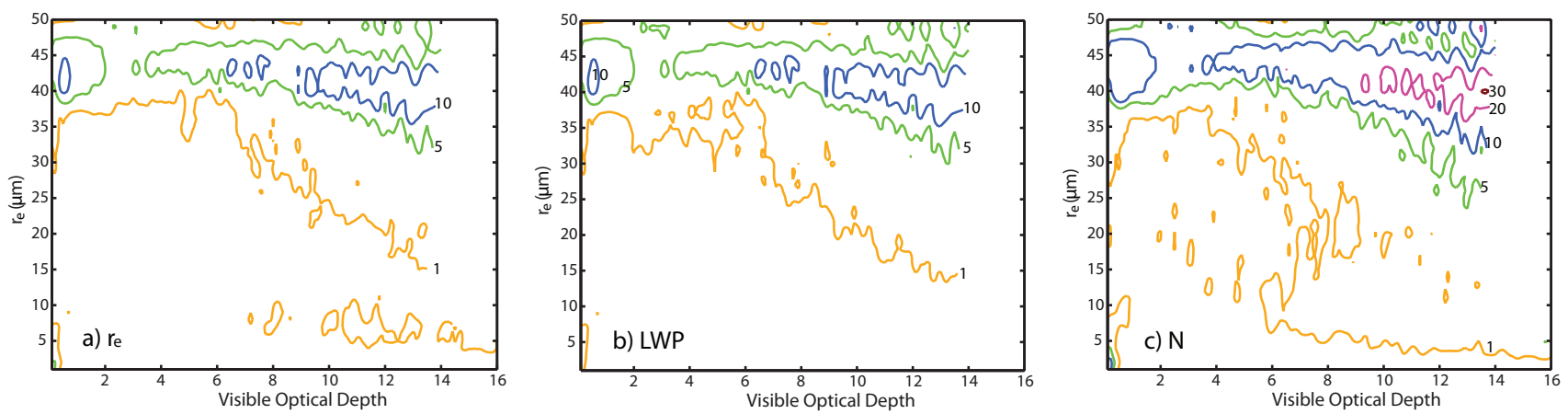

Fig. 10. Calculated uncertainties in retrievals of liquid cloud $r_{\mathrm{e}}, \mathrm{LWP}$ and $N$ that are associated only with the look-up table method outlined in Sect. 4, separate from any errors associated with uncertainties in measurements. Errors (contours) are expressed in percent within a space of $r_{\mathrm{e}}$ an $\tau$ for a cloud with fixed boundaries and a specified atmospheric profile.

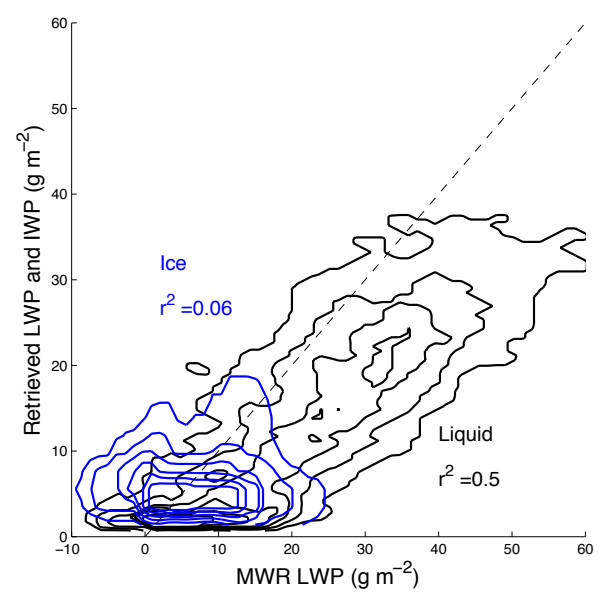

Fig. 11. Linear probability density distributions (contours) for an inter-comparison of retrieved and Microwave Radiometer (MWR) measured LWP. The dashed line is a 1:1 line.

For the sake of intercomparison, we examined how well microphysics retrievals agreed for an intermediate regime between $20 \mathrm{~g} \mathrm{~m}^{-2}$ and $40 \mathrm{~g} \mathrm{~m}^{-2}$, as shown in Fig. 13. For a period between May and September, the average LWP within this range was $29.26 \mathrm{~g} \mathrm{~m}^{-2}$ for the infrared method and $29.62 \mathrm{~g} \mathrm{~m}^{-2}$ for the Dong and Mace method.

Overall, both techniques give very similar retrievals, at least in trends if not always in absolute values. Both approaches reveal a transition in liquid cloud $r_{\mathrm{e}}$ between late spring and summer from approximately $5 \mu \mathrm{m}$ to $10 \mu \mathrm{m}$ along with a commensurate relative decline in optical depth. However, in late spring, the Dong and Mace retrievals of $r_{\mathrm{e}}$ tend to be about one to two micrometers smaller, and this lends itself to as much as a factor of three discrepancy in retrievals of droplet number concentration (Eq. 11). Nonetheless the transition to higher droplet concentrations between spring and summer is reproduced by both methods. In summer, the differences between both approaches are in general very small.

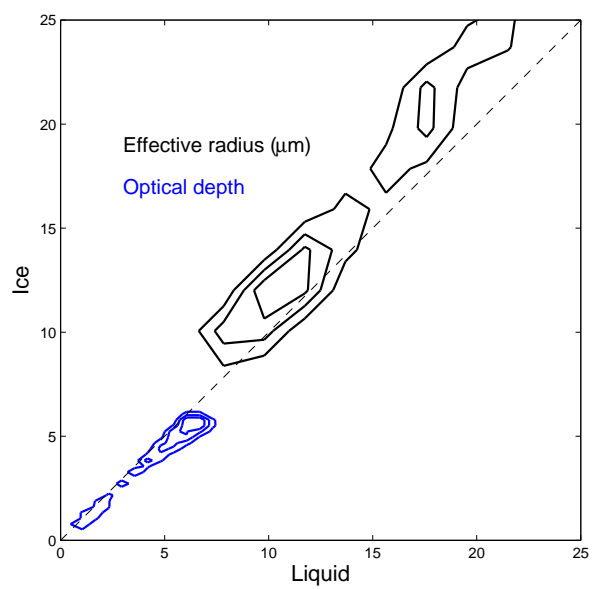

Fig. 12. Linear probability density distributions (contours) for retrieved clouds of "uncertain" phase depending on whether the refractive indices in the retrievals are assumed to be those of ice or liquid. The dashed line is a 1:1 line.

\subsection{Case study}

Figure 14 shows lidar and radar imagery from NSA-AAO for a scene on 13 January 2001 that is both complex while not being unusual. The day is characterised by two cloud layers: a high layer above $4 \mathrm{~km}$ altitude that resembles cirrus fallstreaks, and a lower thin cloud layer at around $1 \mathrm{~km}$ altitude with precipitation falling beneath.

Fig. 15 shows retrieved cloud properties for this case. What is observed is a high cirrus cloud in the beginnings of the day that, with some overlap, transitions to a thin lowlevel cloud. Because the cirrus and lower-level cloud are well separated, cloud retrievals are made here even though the day is largely multi-layered. With a few exceptions, when cloud phase is explicitly retrieved, it indicates that the cirrus cloud is ice and the low-level cloud is liquid. The spectral slope $\chi=\left(\varepsilon_{b} / \varepsilon_{e}\right) /\left(\varepsilon_{e} / \varepsilon_{g}\right)$ used in part to characterise cloud phase 

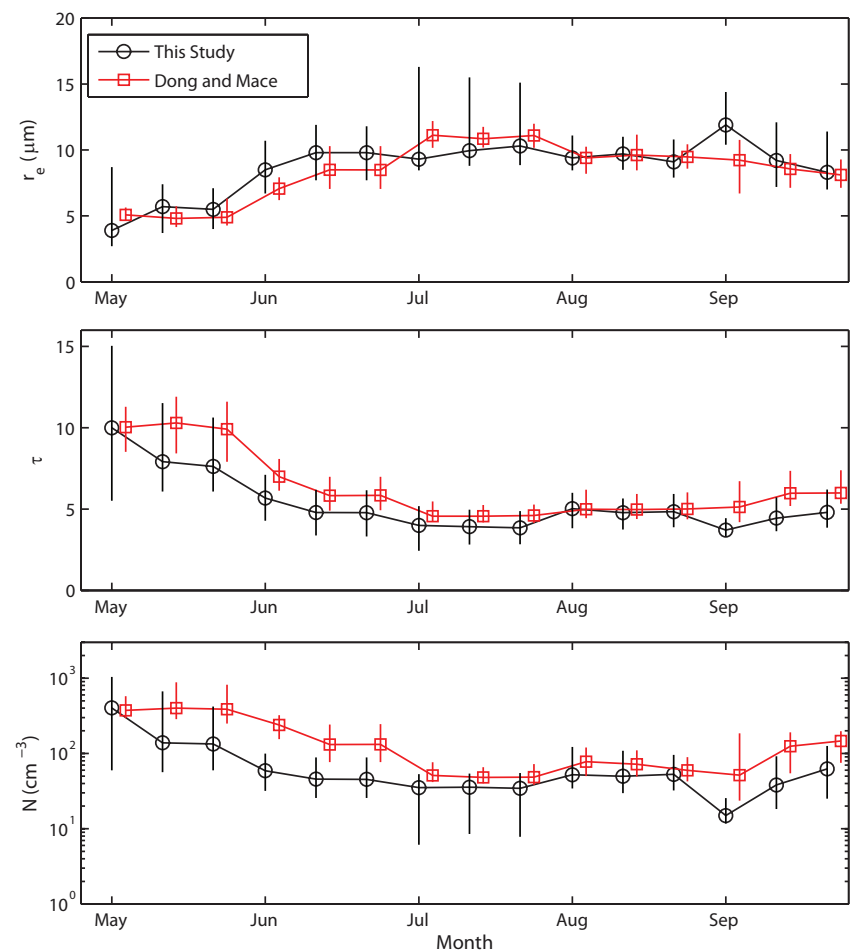

Fig. 13. Calculated in 10-day intervals for the period May to September between 2000 and 2003, retrieved cloud droplet effective radius $r_{\mathrm{e}}$, visible optical depth $\tau$, particle number concentration $N$, using two methods: the method described here (black), and an independent technique based on shortwave transmission and MWR LWP retrievals developed by Dong and Mace (2003b). For the intercomparison, retrievals are constrained to a range of LWP values between $20 \mathrm{~g} \mathrm{~m}^{-2}$ and $40 \mathrm{~g} \mathrm{~m}^{-2}$. Bars represent the range in quartiles.

is relatively consistent within each of these two regions: the low-level cloud has median and (lower, upper] quartile values of $\chi$ that are 1.04 (1.03 1.05) versus $0.90(0.850 .93)$ in the cirrus.

Median and (lower, upper) quartile values for the low-level liquid cloud properties are a thickness of $250(236272) \mathrm{m}$, an emissivity of 0.90 (0.83 0.93), a visible optical depth of 6.1 (5.1 7.2], a droplet effective radius of 4.7 (3.8 6.2) $\mu \mathrm{m}$, droplet concentrations of $192(130434) \mathrm{cm}^{-3}$, and a liquid water path of 22 (15 25) $\mathrm{g} \mathrm{m}^{-2}$. For the ice crystal cirrus, median and (lower, upper) quartile values are a thickness of 589 (237 930) m, an emissivity of 0.09 (0.07 0.16), a visible optical depth of $0.20(0.160 .35)$, an ice crystal effective radius of 48 (39 49) $\mu \mathrm{m}$, ice crystal concentrations of 69 (47 128) litre $^{-1}$, and a liquid water path of $6.1(4.98 .0) \mathrm{g} \mathrm{m}^{-2}$. Given that the ice crystal effective radius retrieval is near the upper limit for retrieval sensitivity of $50 \mu \mathrm{m}$, it is possible that the true sizes are larger and the concentrations lower.
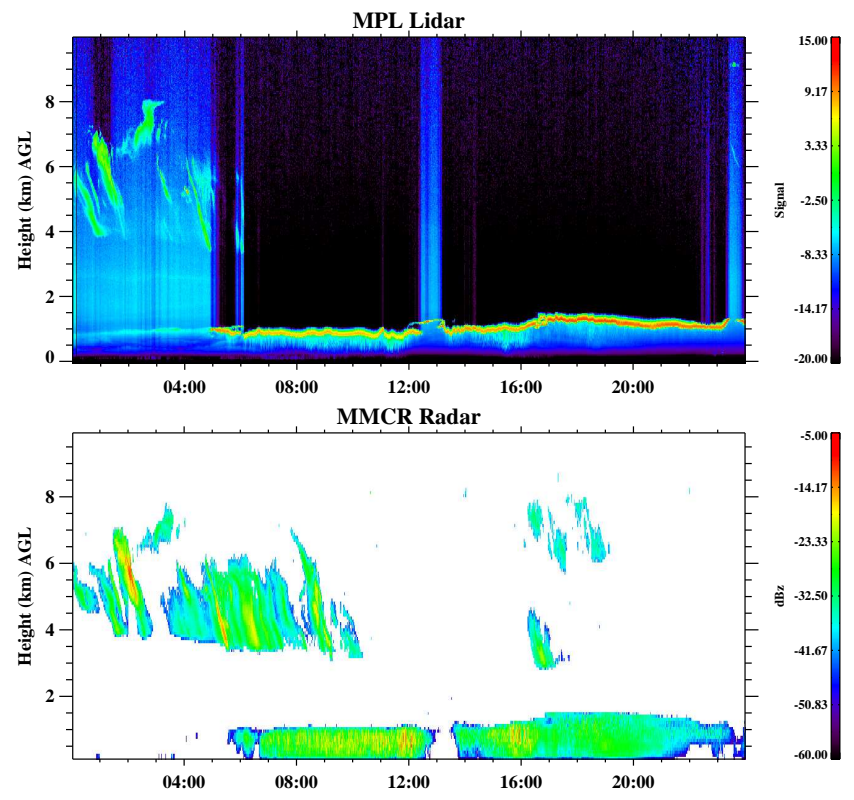

Fig. 14. Lidar and radar returns from NSA-AAO on 13 January, 2001.

\subsection{Seasonal variability}

Figure 16 shows the retrieved seasonable variability in thin cloud properties at NSA-AAO between 2000 and 2003, presented as monthly means. Cloud cover statistics are presented for both all clouds and those graybody clouds with $\varepsilon_{b}<0.95$. The remainder of parameters shown apply only to graybody clouds for which the thermal IR retrieval technique presented here applies. Therefore, the statistics do not represent a true climatology since they omit thicker clouds that radiate as blackbodies.

In general, the statistics are qualitatively consistent with prior studies of the seasonality of Arctic clouds (e.g., Shupe et al., 2005; Kay and Gettelman, 2009; Devasthale et al., 2011). The Arctic is cloudy. Thin graybody clouds are a substantial fraction of the total, comprising about $42 \%$. On average, these clouds are found at low levels with bases below $2 \mathrm{~km}$ altitude. In summer when conditions are warmer, the first cloud layer viewed from the ground is rarely ice. Also in summer, clouds have a higher water path and are more optically thick than in winter. Included for comparison is the seasonal cycle in the MWR liquid water path, which shows that the magnitude of the LWP cycle for both thick and thin clouds approaches a factor of ten. The optical depths and effective radii of all gray-body clouds are intermediate to those of the liquid and ice clouds, but on average they are most closely approximated by the liquid cloud portion.

When ice clouds are present, they have crystal concentrations that are about two orders of magnitude lower than the liquid droplet concentrations and effective radii that are about four times as large. While we lack any direct point for 

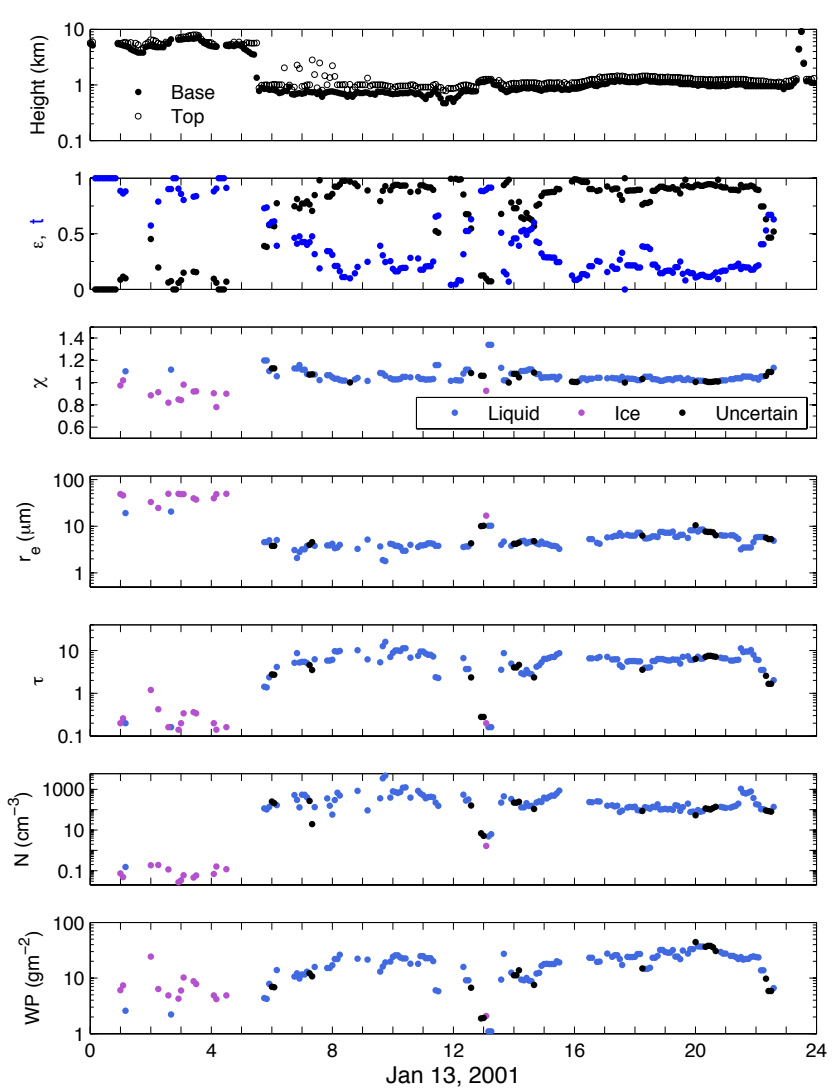

Fig. 15. Retrieved cloud boundaries $H$, emissivity (at $862.5 \mathrm{~cm}^{-1}$ ) and transmissivity (at $1040 \mathrm{~cm}^{-1}$ ), ratio of spectral slopes $\chi=$ $\left(\varepsilon_{b} / \varepsilon_{e}\right) /\left(\varepsilon_{e} / \varepsilon_{g}\right)$, and cloud droplet effective radius $r_{\mathrm{e}}$, visible optical depth $\tau$, particle number concentration $N$, and condensate water path WP, for the scene in Fig. 14 observed at NSA-AAO on 13 January 2001.

intercomparison, in-situ aircraft observations of ice crystal concentrations from the Arctic tend to be lower than those that are retrieved (e.g., Jouan et al., 2012). One reason for the discrepancy could be that analyses of in-situ ice crystal concentration measurements sometimes use an experimental algorithm that removes particles with unusually short interarrival times at airborne probes, assuming these particles arise from ice crystal shattering on instrument inlets. Provided that these algorithms are appropriately applied, another possibility for the discrepancy is that the retrieval method discussed here is in error because it is limited to clouds (not below-cloud precipitation) with effective radii smaller than $50 \mu \mathrm{m}$ : where ice crystal effective radii are in fact larger than $50 \mu \mathrm{m}$, retrieved ice crystal number concentrations could be erroneously high.
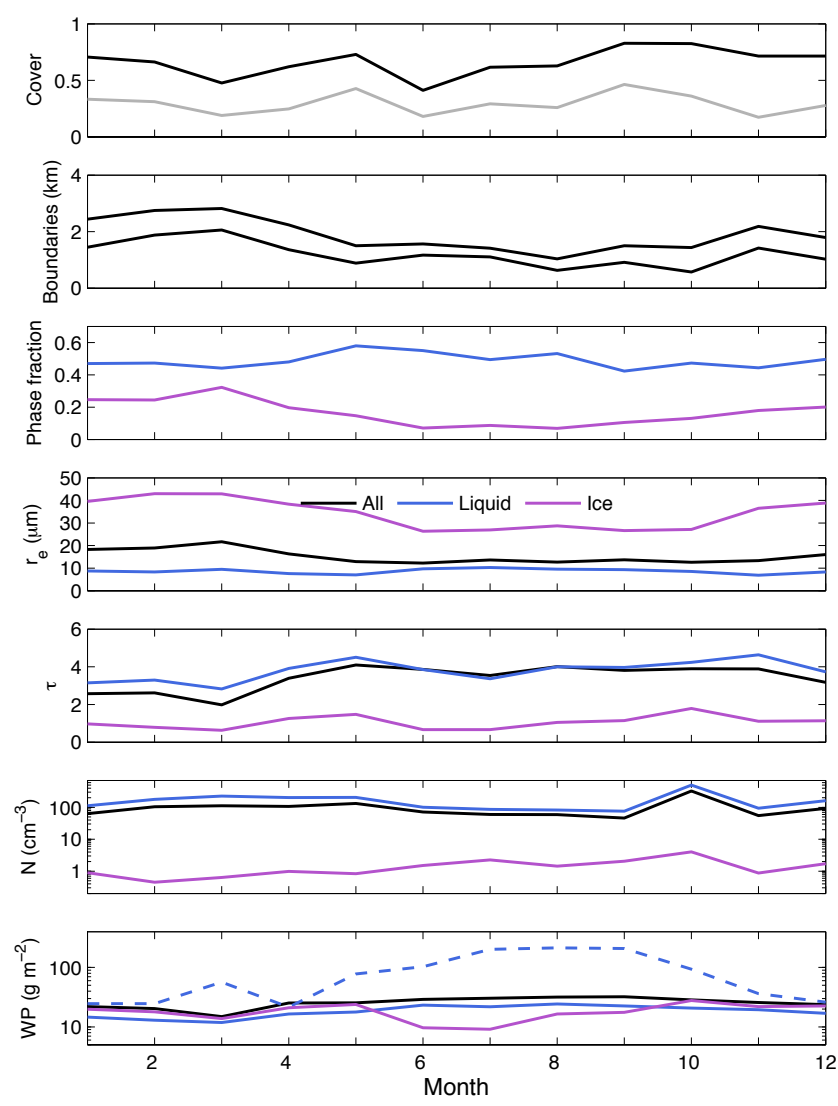

Fig. 16. Monthly averages of retrieved graybody cloud properties for the 2000 to 2003 time period at NSA-AAO. Top panel: retrieved cloud cover of all (black) and graybody (gray) clouds. Lower panels: for graybody clouds only, the cloud boundaries, the fraction of clouds that were identified as liquid (blue) or ice (magenta), the cloud particle effective radius $r_{\mathrm{e}}$ of liquid, ice and all (black) clouds, the cloud optical depth $\tau$, the cloud particle number concentration (liquid $\left(\mathrm{cm}^{-3}\right)$, ice $\left(\mathrm{cm}^{-3}\right)$ ), and the water path WP. The dashed line for WP represents MWR retrievals for all liquid clouds.

\section{Conclusions}

A method has been developed for the retrieval of Arctic cloud microphysical and macrophysical properties based on cloudy thermal emission and stratospheric ozone cloudy thermal transmission. For both liquid and ice clouds, two emissivity micro-windows are selected in the atmospheric window based on the sensitivity of the particle absorption coefficient to particle effective radius $r_{\mathrm{e}}$. Cloud micro-structure properties are obtained by matching estimates of cloud emissivity and transmissivity from measurements with calculated values from a look-up table. The retrieval technique is limited to graybody clouds with cloud optical depths $\tau$ less than 16 and cloud particle effective radii $r_{\mathrm{e}}$ smaller than $50 \mu \mathrm{m}$.

Cloud phase is determined from the ratios of three emissivity micro-windows within the atmospheric window. These can be paired to neatly separate cloud phase for much of the 
plausible space in $\left(r_{\mathrm{e}}, \tau\right)$. The phase retrieval reflects the radiative properties of the clouds: mixed-phased clouds might be identified as being liquid if the ice crystals contribute negligibly to their thermal emission.

Error analysis indicates that the method's main sources of retrieval error come from uncertainties in measured cloud base temperature, surface thermal radiance, and the stratospheric ozone profile. Because retrievals are constrained by both cloud transmittance and emissivity, they display very low sensitivity to water vapour. The respective $95 \%$ confidence retrieval errors in $r_{\mathrm{e}}, \tau$, WP, and $N$ are about $10 \%$, $20 \%, 16 \%$ and $38 \%$ for liquid cloud, and about $10 \%, 20 \%$, $16 \%$ and $55 \%$ for ice clouds. The retrievals of cloud microphysical properties require an a priori determination of cloud phase. Where phase cannot be determined, or is in error, the bias in retrievals of $r_{\mathrm{e}}$ and $\tau$ is approximately $15 \%$.

The thermal IR based method described here is particularly well suited to optically thin clouds that can be difficult to characterise using other remote sensing approaches. For example, the average liquid water path retrieved by the microwave radiometer (MWR) between the months of November and February is $28 \mathrm{~g} \mathrm{~m}^{-2}$. Such clouds are optically thin in the thermal IR, but they lie within the MWR retrieval noise.

Also, retrieval methods based on solar transmission can be well suited for describing cloud properties in the summer (e.g., Dong and Mace, 2003a), but they are inapplicable during the winter night. By contrast, thermal emission is year round. The primary limitations of the thermal IR approach discussed here are twofold. First, it requires a fairly extensive grouping of measurements to achieve its stated level of accuracy. Second, it requires that clouds cannot approximate blackbodies. Clouds tend to be most optically thick in summer when this method could be used in combination with other approaches.

\section{Appendix A}

\section{Sensitivity to water vapour}

For the emissivity measurement calculations described here, the contribution of water vapour to the measured signal is not subtracted (Eq. 6) because its contribution is, for the most part, negligible. Estimated retrieval uncertainties associated with water vapour were estimated to be within $1 \%$ for $\tau, r_{\mathrm{e}}$ and WP.

For comparison, a prior study by Turner (2005) described the "MIXCRA" algorithm, which, while highly flexible and accurate in its application of AERI measurements to Arctic cloud retrievals (Turner and Eloranta, 2008), was nonetheless constrained to scenes with precipitable water vapour (PWV) amounts less than $1 \mathrm{~cm}$. This precondition could be removed, but only if the cloud phase was known a priori, as it was

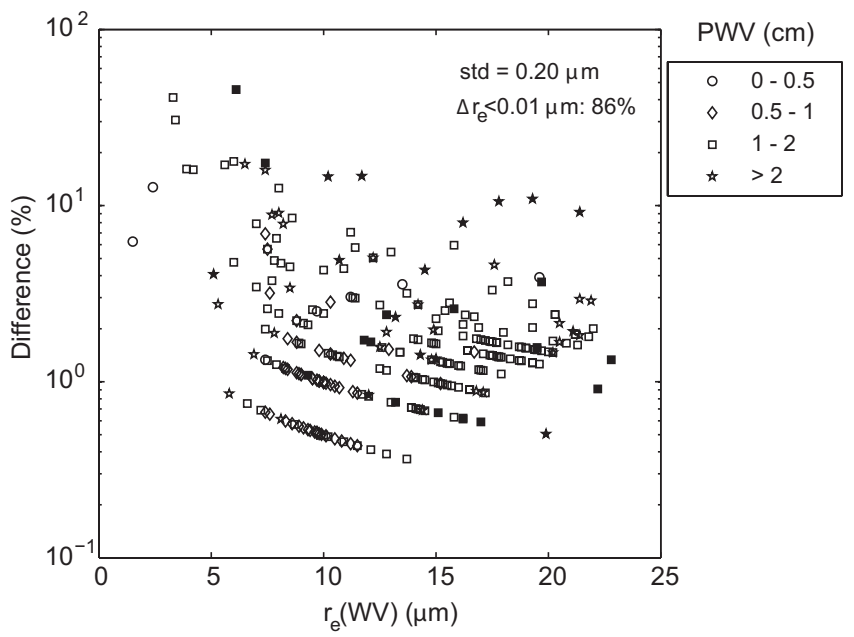

Fig. A1. Percent difference in retrievals of $r_{e}$ associated with not subtracting water vapor contributions to measured downwelling radiance in emissivity calculations (Eq. 6), versus retrieved values with water vapor subtracted, as a function of the precipitable water vapor content (PWV) of the atmosphere. The only differences plotted are those in the $14 \%$ of cases with differences in $r_{e}>0.01 \mu \mathrm{m}$. Negative differences are in closed circles.

only the phase identification component of MIXCRA that involved frequencies outside the atmospheric window.

By contrast, the retrievals described here, including those of phase, are based only on measurements within the atmospheric window where water lacks single-molecule rotational or vibrational fundamental modes. The disadvantage of this approach is that differences in the absorption properties of ice and liquid clouds are not always clearly separated. Also, water vapour continuum absorption does remain in the window. Nonetheless, water vapour emission is implicitly factored into the retrievals through comparisons of transmissivity inside and just outside the $1040 \mathrm{~cm}^{-1}$ ozone band that are used to calculate cloud transmissivity (Fig. 8). Moreover, cloud emissivity estimates are evaluated within "micro-windows" where atmospheric absorption and emission by water vapour is particularly small.

Figure A1, shows the influence of water vapour on the retrievals of $r_{\mathrm{e}}$. Not subtracting water vapour in estimates of cloud emissivity causes differences in retrieved values of $r_{\mathrm{e}}$. In $86 \%$ of cases the difference is less than $0.01 \mu \mathrm{m}$, which is the precision of the retrieval technique. In the remainder of cases the difference is generally still very small, in the vicinity of 1 to 2 percent. In only a very few cases is the difference in excess of $10 \%$, although still less than $1 \mu \mathrm{m}$.

What is interesting is that cases with relatively high errors are usually, but not necessarily associated with high values of PWV. More important than the absolute value of PWV are the relative contributions of water vapour and cloud to downwelling radiance. Naturally, these two quantities tend to covary with temperature. Drier conditions may be associated 
with lower water vapour emission, but they are also associated with thinner, less strongly emitting clouds. In this case, the contribution of water vapour to the measured signal may be much larger than is typical, if still small.

Acknowledgements. This work was supported by the National Science Foundation through grants 0303962 and 0649570, the Clean Air Task Force, through NOAA by grant 2308014, and the Ministry of Science and Technology of China through grant 2013CB955804. We are grateful to the late P. V. Hobbs for having provided aircraft data, the Word Data Center for Remote Sensing of the Atmosphere for ozone profile data, X. Dong for his cloud retrieval product, and Jay Mace and Sally Benson for plots of the lidar and radar signals.

Edited by: A. Kokhanovsky

\section{References}

Beesley, J. A.: Estimating the effect of clouds on the arctic surface energy budget, J. Geophys. Res., 105, 10103-10117, 2000.

Bourdages, L., Duck, T. J., Lesins, G., Drummond, J. R., and Eloranta, E. W.: Physical properties of High Arctic tropospheric particles during winter, Atmos. Chem. Phys., 9, 6881-6897, doi:10.5194/acp-9-6881-2009, 2009.

Campbell, J. R., Hlavka, D. L., Welton, E. J., Flynn, C. J., Turner, D. D., Spinhirne, J. D., and Scott, V. S.: Full-time eye-safe cloud and aerosol lidar observation at atmospheric radiation measurement program sites: Instruments and data processing, J. Atmos. Ocean. Tech., 19, 431-442, 2002.

Cesana, G., Kay, J. E., Chepfer, H., English, J. M., and de Boer, G.: Ubiquitous low-level liquid-containing Arctic clouds: New observations and climate model constraints from CALIPSOGOCCP, Geophys. Res. Lett., 39, L20804, http://dx.doi.org/10. 1029/2012GL053385, 2012.

Chylek, P., Robinson, S., Dubey, M. K., King, M. D., Fu, Q., and Clodius, W. B.: Comparison of near-infrared and thermal infrared cloud phase detections, J. Geophys. Res., 111, D20203, doi:10.1029/2006JD007140, 2006.

Clough, S. A., Iacono, M. J., and Moncet, J. L.: Line-by-line calculations of atmospheric fluxes and cooling rates: application to water vapour, J. Geophys. Res., 97, 15761-15785, 1992.

Comstock, J. M., D’Entremont, R., DeSlover, D., Mace, G. G., Matrosov, S. Y., McFarlane, S. A., Minnis, P., Mitchell, D., Sassen, K., Shupe, M. D., et al.: An intercomparison of microphysical retrieval algorithms for upper-tropospheric ice clouds, Bull. Am. Meteorol. Soc., 88, 191-204, 2007.

Curry, J. A., Rossow, W. B., Randall, D., and Schramm, J. L.: Overview of Arctic cloud and radiation characteristics, J. Climate, 9, 1731-1764, 1996.

Curry, J. A., Hobbs, P. V., King, M. D., Randall, D. A., Minnis, P., Isaac, G. A., Pinto, J. O., Uttal, T., Bucholtz, A., Cripe, D. G., Gerber, H., Fairall, C. W., Garrett, T. J., Hudson, J., Intrieri, J. M., Jakob, C., Jensen, T., Lawson, P., Marcotte, D., Nguyen, L., Pilewskie, P., Rangno, A., Rogers, D. C., Strawbridge, K. B., Valero, F. P. J., Williams, A. G., and Wylie, D.: FIRE Arctic Clouds Experiment, Bull. Amer. Meteor. Soc., 81, 5-29, 2000. de Boer, G., Collins, W. D., Menon, S., and Long, C. N.: Using surface remote sensors to derive radiative characteristics of MixedPhase Clouds: an example from M-PACE, Atmos. Chem. Phys., 11, 11937-11949, doi:10.5194/acp-11-11937-2011, 2011.

Dergach, A. L., Zabrodsky, G. M., and Morachevsky, V. G.: The results of a complex investigation of the type St-Sc clouds and fogs in the Arctic, Bull. Acad. Sci. USSR, Geophys. Ser., 1, 66$70,1960$.

Devasthale, A., Tjernström, M., Karlsson, K.-G., Thomas, M. A., Jones, C., Sedlar, J., and Omar, A. H.: The vertical distribution of thin features over the Arctic analysed from CALIPSO observations Part I: Optically thin clouds, Tellus B, 63, 77-85, doi:10.1111/j.1600-0889.2010.00516.x, 2011.

Dong, X. and Mace, G. G.: Arctic stratus cloud properties and radiative forcing derived from ground-based data collected at Barrow, Alaska, J. Climate, 16, 445-461, 2003 a.

Dong, X. and Mace, G. G.: Arctic stratus cloud properties and radiative forcing derived from ground-based data collected at Barrow, Alaska, J. Climate, 16, 445-461, 2003b.

Dong, X., Minnis, P., and Xi, B.: A climatology of midlatitude continental clouds from the ARM SGP central facility: Part I: Lowlevel cloud macrophysical, microphysical, and radiative properties, J. Climate, 18, 1391-1410, 2005.

Field, P. R., Wood, R., Brown, R. A., Kaye, P. H., Hirst, E., Greenway, R., and Smith, J. A.: Ice particle interarrival times measured with a Fast FSSP, J. Atmos. Ocean. Technol., 20, 249-261, 2003.

Foot, J. S.: Some observations of the optical properties of clouds, Part 2, Cirrus, Q. J. R. Meteorol. Soc., 114, 145-164, 1988.

Francis, J. A. and Hunter, E.: New insight into the disappearing Arctic sea ice, Eos Trans. AGU, 87, 509-511, doi:10.1029/2006EO460001, 2006.

Francis, J. A. and Hunter, E.: Changes in the fabric of the Arctic's greenhouse blanket, Env. Res. Lett., 2, 045011-+, doi:10.1088/1748-9326/2/4/045011, 2007.

Fridlind, A. M., Ackerman, A. S., McFarquhar, G., Zhang, G., Poellot, M. R., DeMott, P. J., Prenni, A. J., and Heymsfield, A. J.: Ice properties of single-layer stratocumulus during the MixedPhase Arctic Cloud Experiment: 2. Model results, J. Geophys. Res., 112, D24202, doi:10.1029/2007JD008646, 2007.

Garrett, T. J. and Zhao, C.: Increased Arctic cloud longwave emissivity associated with pollution from mid-latitudes, Nature, 440, 787-789, doi:10.1038/nature04636, 2006.

Garrett, T. J., Radke, L. F., and Hobbs, P. V.: Aerosol effects on the cloud emissivity and surface longwave heating in the Arctic, J. Atmos. Sci., 59, 769-778, 2002.

Garrett, T. J., Zhao, C., Dong, X., Mace, G. G., and Hobbs, P. V.: Effects of varying aerosol regimes on low-level Arctic stratus, Geophys. Res. Lett., 31, 17105-17109, 2004.

Han, W., Stamnes, K., and Lubin, D.: Retrieval of surface and cloud properties in the Arctic from NOAA AVHRR measurements, J. Appl. Meteor., 38, 989-1012, 1999.

Hansen, J. E. and Travis, L. D.: Light scattering in planetary atmospheres, Space Sci. Rev., 16, 527-610, 1974.

Harrington, J. Y., Feingold, G., and Cotton, W. R.: Radiative impacts on the growth of a population of drops within simulated summertime Arctic stratus, J. Atmos. Sci., 57, 766-785, 2000.

Hildenbrand, B., Bittner, M., Baier, F., and Erbertseder, T.: European Rocket and Balloon Programmes and Related Research, Vol. 530, chap. Derivation of vertically resolved ozone pro- 
files by assimilating total column ozone data into the 3D-NCARROSE chemical-transport model, 487-491, 2003.

Hobbs, P. V. and Rangno, A. L.: Microstructure of low and middlelevel clouds over the beaufort sea, Q. J. R. Meteorol. Soc., 124, 2035-2071, 1998a.

Hobbs, P. V. and Rangno, A. L.: Microstructures of low and middlelevel clouds over the Beaufort Sea, Quart. J. Roy. Meteor. Soc., 124, 2035-2071, 1998b.

Hobbs, P. V., Rangno, A. L., Shupe, M., and Uttal, T.: Airborne studies of cloud structures over the Arctic ocean comparisons with retrievals from ship-based remote sensing measurements, J. Geophys. Res., 106, 15029-15044, 2001.

Jayaweera, K. O. L. F. and Ohtake, T.: Concentration of ice crystals in Arctic Stratus Clouds, Geophys. Res. Lett., 9, 94-97, 1982.

Jouan, C., Girard, E., Pelon, J., Gultepe, I., Delanoë, J., and Blanchet, J.-P.: Characterization of Arctic ice cloud properties observed during ISDAC, J Geophys Res, 117, D23207, doi:10.1029/2012JD017889, 2012.

Jourdan, O., Mioche, G., Garrett, T. J., Schwarzenböck, A., Vidot, J., Xie, Y., Shcherbakov, V., Yang, P., and Gayet, J.-F.: Coupling of the microphysical and optical properties of an Arctic nimbostratus cloud during the ASTAR 2004 experiment: Implications for light-scattering modeling, J. Geophys. Res., 115, D23206, doi:10.1029/2010JD014016, 2010.

Kay, J. E. and Gettelman, A.: Cloud influence on and response to seasonal Arctic sea ice loss, J. Geophys. Res., 114, D18204, doi:10.1029/2009JD011773, 2009.

Kay, J. E., L'Ecuyer, T., Gettelman, A., Stephens, G., and O’Dell, C.: The contribution of cloud and radiation anomalies to the 2007 Arctic sea ice extent minimum, Geophys. Res. Lett., 35, L08503, doi:10.1029/2008GL033451, 2008.

Kay, J. E., Holland, M. M., Bitz, C. M., Blanchard-Wrigglesworth, E., Gettelman, A., Conley, A., and Bailey, D.: The Influence of Local Feedbacks and Northward Heat Transport on the Equilibrium Arctic Climate Response to Increased Greenhouse Gas Forcing, J. Climate, 25, 5433-5450, doi:10.1175/JCLI-D-1100622.1, http://dx.doi.org/10.1175/JCLI-D-11-00622.1, 2012.

King, M. D., Platnick, S., Yang, P., Arnold, G. T., Gray, M. A., Riedi, J. C., Ackerman, S. A., and Liou, K. N.: Remote sensing of liquid water and ice cloud optical thickness and effective radius in the Arctic: Application of airborne multispectral MAS data, J. Atmos. Ocean. Tech., 21, 857-875, 2004.

Klein, S. A., McCoy, R. B., Morrison, H., Ackerman, A. S., Avramov, A., Boer, G. d., Chen, M., Cole, J. N. S., Del Genio, A. D., Falk, M., Foster, M. J., Fridlind, A., Golaz, J.-C., Hashino, T., Harrington, J. Y., Hoose, C., Khairoutdinov, M. F., Larson, V. E., Liu, X., Luo, Y., McFarquhar, G. M., Menon, S., Neggers, R. A. J., Park, S., Poellot, M. R., Schmidt, J. M., Sednev, I., Shipway, B. J., Shupe, M. D., Spangenberg, D. A., Sud, Y. C., Turner, D. D., Veron, D. E., Salzen, K. v., Walker, G. K., Wang, Z., Wolf, A. B., Xie, S., Xu, K.-M., Yang, F., and Zhang, G.: Intercomparison of model simulations of mixed-phase clouds observed during the ARM Mixed-Phase Arctic Cloud Experiment. I: single-layer cloud, Q. J. Roy. Meteorol. Soc., 135, 979-1002, doi:10.1002/qj.416, http://dx.doi.org/10.1002/qj.416, 2009.

Knuteson, R. O., Revercomb, H. E., Best, F. A., Ciganovich, N. C., Dedecker, R. G., Dirkx, T. P., Ellington, S. C., Feltz, W. F., Garcia, R. K., Howell, H. B., Smith, W. L., Short, J. F., and Tobin, D. C.: Atmospheric emitted radiance interferometer. Part I: In- strument design, J. Atmos. Oceanic Technol., 21, 1763-1776, 2004.

Lampert, A., Ehrlich, A., Dörnbrack, A., Jourdan, O., Gayet, J.F., Mioche, G., Shcherbakov, V., Ritter, C., and Wendisch, M. Microphysical and radiative characterization of a subvisible midlevel Arctic ice cloud by airborne observations- a case study, Atmos. Chem. Phys., 9, 2647-2661, doi:10.5194/acp-9-26472009, 2009.

Lapaolo, M., Godin-Beekmann, S., DelFrate, F., Casadio, S., Petitdidier, M., McDermid, I. S., Leblanc, T., D. Swart, Y. M., Hansen, G., and Stebel, K.: Gome ozone profiles retrieved by neural network techniques: A global validation with lidar measurements, J. Quant. Spectr. Rad. Transfer, 107, 105-119, 2007.

Liljegren, J. C., Clothiaux, E. E., Mace, G. G., Kato, S., and Dong, $\mathrm{X}$.: A new retrieval for cloud liquid water path using a groundbased microwave radiometer and measurements of cloud temperature, J. Geophys. Res., 106, 14485-14500, 2001.

Mahesh, A., Walden, V. P., and Warren, S. G.: Ground-based infrared remote sensing of cloud properties over the Antarctic plateau. Part II: Cloud optical depths and particle sizes, J. Appl. Meteor., 40, 1279-1294, 2001.

Marchand, R., Ackerman, T., Westwater, E. R., Clough, S. A., Pereira, K. C., and Liljegren, J. C.: An assessment of microwave absorption models and retrievals of cloud liquid water using clear-sky data, J. Geophys. Res., 108, 4773, doi:10.1029/2003JD003,843, 2003.

McFarquhar, G. M., Ghan, S., Verlinde, J., Korolev, A., Strapp, J. W., Schmid, B., Tomlinson, J. M., Wolde, M., Brooks, S. D., Cziczo, D., Dubey, M. K., Fan, J., Flynn, C., Gultepe, I., Hubbe, J., Gilles, M. K., Laskin, A., Lawson, P., Leaitch, W. R., Liu, P., Liu, X., Lubin, D., Mazzoleni, C., MacDonald, A.-M., Moffet, R. C., Morrison, H., Ovchinnikov, M., Shupe, M. D., Turner, D. D., Xie, S., Zelenyuk, A., Bae, K., Freer, M., and Glen, A.: Indirect and Semi-direct Aerosol Campaign, Bull. Am. Meteorol. Soc., 92, 183-201, doi:10.1175/2010BAMS2935.1, 2011.

Morrison, H., Zuidema, P., Ackerman, A. S., Avramov, A., de Boer, G., Fan, J., Fridlind, A. M., Hashino, T., Harrington, J. Y., Luo, Y., Ovchinnikov, M., and Shipway, B.: Intercomparison of cloud model simulations of Arctic mixed-phase boundary layer clouds observed during SHEBA/FIRE-ACE, Journal of Advances in Modeling Earth Systems, 30, M06003, doi:10.1029/2011MS000066, 2011.

Nasiri, S. L. and Kahn, B. H.: Limitations of bispectral infrared cloud phase determination and potential for improvement, J. Appl. Meteorol. Clim., 47, 2895-2910, 2008.

Peppler, R. A., Long, C. N., Sisterson, D. L., Turner, D. D., Bahrmann, C. P., Christensen, S. W., Doty, K. J., C., E. R., Halter, T. D., Ivey, M. D., Keck, N. N., Kehoe, K. E., Liljegren, J. C., Macduf, M. C., Mather, J. H., McCord, R. A., Monroe, J. W., Moore, S. T., Nitschke, K. L., Orr, B. W., Perez, R. C., Perkins, B. D., Richardson, S. J., Sonntag, K. L., Voyles, J. W., , and Wagener, R.: An overview of ARM Program Climate Research Facility data quality assurance, The Open Atmos. Sci. J., 2, 192-216, doi:10.2174/1874282300802010192, 2008.

Pinto, J. O., Curry, J. A., and Intrieri, J. M.: Cloud-aerosol interactions during autumn over Beaufort Sea, J. Geophys. Res., 106, 15077-15098, doi:10.1029/2000JD900267, 2001.

Rangno, A. L. and Hobbs, P. V.: Ice particles in stratiform clouds in the Arctic and possible mechanisms for the production of 
high ice concentrations, J. Geophys. Res., 106, 15065-15076, doi:10.1029/2000JD900286, 2001.

Riedi, J., Marchant, B., Platnick, S., Baum, B., Thieuleux, F., Oudard, C., Parol, F., Nicolas, J., and Dubuisson, P.: Cloud thermodynamic phase inferred from merged POLDER and MODIS data, Atmos. Chem. Phys. Disc., 7, 14103-14137, 2007.

Shupe, M. D.: Clouds at Arctic Atmospheric Observatories. Part II: Thermodynamic Phase Characteristics, Journal of Applied Meteorology and Climatology, 50, 645-661, doi:10.1175/2010JAMC2468.1, 2011.

Shupe, M. D., Uttal, T., and Matrosov, S. Y.: Arctic cloud microphysics retrievals from surface-based remote sensors at SHEBA, J. Appl. Meteor., 44, 1544-1562, 2005.

Shupe, M. D., Matrosov, S. Y., and Uttal, T.: Arctic mixed-phase cloud properties derived from surface-based sensors at SHEBA, J. Atmos. Sci., 63, 697-711, 2006.

Smith, W. S. and Kao, C. Y.: Numerical simulations of observed Arctic stratus clouds using a second-order turbulence closure model, J. Appl. Meteor., 35, 47-59, 1996.

Stamnes, K., Tsay, S. C., Wiscombe, W., and Jayaweera, K.: A numerically stable algorithm for discrete-ordinate-method radiative transfer in multiple scattering and emitting layered media, Appl. Opt., 27, 2502-2509, 1988.

Strabala, K. I., Ackerman, S. A., and Menzel, W. P.: Cloud properties inferred from 8-12 $\mu \mathrm{m}$ data, J. Appl. Meteor., 33, 212-229, 1994.

Tietze, K. V., Riedi, J., Stohl, A., and Garrett, T. J.: Space-based evaluation of interactions between aerosols and low-level Arctic clouds during the Spring and Summer of 2008, Atmos. Chem. Phys., 11, 3359-3373, doi:10.5194/acp-11-3359-2011, 2011.

Turner, D. and Eloranta, E.: Validating Mixed-Phase Cloud Optical Depth Retrieved From Infrared Observations With High Spectral Resolution Lidar, Geoscience and Remote Sensing Letters, IEEE, 5, 285-288, doi:10.1109/LGRS.2008.915940, 2008.

Turner, D. D.: Arctic Mixed-Phase Cloud Properties from AERI Lidar Observations: Algorithm and Results from SHEBA, J. Appl. Meteorol., 44, 427-444, doi:10.1175/JAM2208.1, 2005.

Turner, D. D., Ackerman, S. A., Baum, B. A., Revercomb, H. E., and Yang, P.: Cloud phase determination using ground-based AERI observations at SHEBA, J. Appl. Meteor., 42, 701-715, 2003.

Uppala, S., Kallberg, P., Simmons, A., Andrae, U., da Costa Bechtold, V., Fiorino, M., Gibson, J., Haseler, J., Hernandez, A., Kelly, G., Li, X., Onogi, K., Saarinen, S., Sokka, N., Allan, R., Andersson, E., Arpe, K., Balmaseda, M., Beljaars, A., van de Berg, L., Bidlot, J., Bormann, N., Caires, S., Chevallier, F., Dethof, A., Dragosavac, M., Fisher, M., Fuentes, M., Hagemann, S., Holm, E., Hoskins, B., Isaksen, L., Janssen, P., Jenne, R., McNally, A., Mahfouf, J.-F., Morcrette, J.-J., Rayner, N., Saunders, R., Simon, P., Sterl, A., Trenberth, K., Untch, A., Vasiljevic, D., Viterbo, P., and Woollen, J.: The ERA-40 re-analysis, Quart. J. Roy. Meteor. Soc., 131, 2961-3012, 2005. van Diedenhoven, B., Fridlind, A. M., Ackerman, A. S., Eloranta, E. W., and McFarquhar, G. M.: An evaluation of ice formation in large-eddy simulations of supercooled Arctic stratocumulus using ground-based lidar and cloud radar, J. Geophys. Res.-Atmos. 114, D10203, doi:10.1029/2008JD011198, 2009.

Verlinde, J., Harrington, J. Y., McFarquhar, G. M., Yannuzzi, V. T., Avramov, A., Greenberg, S., Johnson, N., Zhang, G., Poellot, M. R., Mather, J. H., Turner, D. D., Eloranta, E. W., Zak, B. D., Prenni, A. J., Daniel, J. S., Kok, G. L., Tobin, D. C., Holz, R., Sassen, K., Spangenberg, D., Minnis, P., Tooman, T. P., Ivey, M. D., Richardson, S. J., Bahrmann, C. P., Shupe, M., DeMott, P. J., Heymsfield, A. J., and Shofield, R.: The Mixed-Phase Arctic Cloud Experiment, Bull. Amer. Meteorol. Soc., 88, 205-221, 2007.

Wang, X. and Key, J. R.: Recent trends in Arctic surface, cloud, and radiation properties from space, Science, 299, 1725-1728, 2003.

Wang, X. and Key, J. R.: Arctic surface, cloud, and radiation properties based on the AVHRR polar pathfinder dataset. Part I: Spatial and temporal characteristics, J. Climate, 18, 2558-2574, 2005.

Warren, S. G.: Optical constants of ice from the ultraviolet to the microwave, Appl. Opt., 23, 1206-1225, 1984.

Warren, S. G. and Brandt, R. E.: Optical constants of ice from the ultraviolet to the microwave: A revised compilation, J. Geophys Res., 113, D14220, doi:10.1029/2007JD009744, 2008.

Wieliczka, D. M., Weng, S., and Querry, M. R.: Wedge shaped cell for highly absorbent liquids: infrared optical constants of water, Appl. Opt., 28, 1714-1719, 1989.

Wiscombe, W. J.: Improved Mie scattering algorithms, Appl. Opt., 19, 1505-1509, 1980.

Witte, H. J.: Airborne observations of cloud particles and infrared flux density in the Arctic, Master's thesis, University of Washington, 1968.

Xiong, X., Lubin, D., Li, W., and Stamnes, K.: A critical examination of satellite cloud retrieval from AVHRR in the Arctic using SHEBA data, J. Appl. Meteor., 41, 1195-1209, 2002.

Zhao, C. and Garrett, T. J.: Ground-based remote-sensing of precipitation in the Arctic, J. Geophys. Res., 113, D14204, doi:10.1029/2007JD009222, 2008. 